PRISCILA FREIRE DA SILVA CEZARIO

\title{
SAÚDE E SEGURANÇA DO TELETRABALHADOR
}

\author{
Dissertação de Mestrado
}

Orientador: Professor Titular Dr. Nelson Mannrich

UNIVERSIDADE DE SÃO PAULO

FACULDADE DE DIREITO

São Paulo - SP

2019 

PRISCILA FREIRE DA SILVA CEZARIO

\title{
SAÚDE E SEGURANÇA DO TELETRABALHADOR
}

\begin{abstract}
Dissertação de Mestrado apresentada à Banca Examinadora do Programa de Pós-Graduação em Direito, da Faculdade de Direito da Universidade de São Paulo, como exigência parcial para obtenção do título de Mestre em Direito, na área de concentração Direito do Trabalho e da Seguridade Social (DTBS), sob a orientação do Professor Titular Dr. Nelson Mannrich.
\end{abstract}

UNIVERSIDADE DE SÃO PAULO

FACULDADE DE DIREITO

São Paulo - SP 


\section{Catalogação na Publicação \\ Serviço de Processos Técnicos da Biblioteca da}

Faculdade de Direito da Universidade de São Paulo

Cezario, Priscila Freire da Silva

Saúde e segurança do teletrabalhador / Priscila Freire da Silva Cezario. -São Paulo, 2019.

274 p. ; $30 \mathrm{~cm}$.

Dissertação (Mestrado) - Programa de Pós-Graduação em Direito,

Faculdade de Direito, Universidade de São Paulo, São Paulo, 2019.

Orientador: Nelson Mannrich.

1. Teletrabalho. 2. Teletrabalhador. 3. Saúde e segurança. 4. Ergonomia.

5. Duração do trabalho. I. Mannrich, Nelson, orient. II. Título. 


\section{FOLHA DE AVALIAÇÃO}

Nome: Priscila Freire da Silva Cezario

Título: Saúde e segurança do teletrabalhador

Dissertação de Mestrado apresentada à Banca Examinadora do Programa de Pós-Graduação em Direito, da Faculdade de Direito da Universidade de São Paulo, como exigência parcial para obtenção do título de Mestre em Direito, na área de concentração Direito do Trabalho e da Seguridade Social (DTBS), sob a orientação do Professor Titular Dr. Nelson Mannrich.

Aprovada em:

Banca Examinadora

Prof. Dr.

Instituição:

Julgamento:

Prof. Dr.

Instituição:

Julgamento:

Prof. Dr.

Instituição:

Julgamento: 



\section{AGRADECIMENTOS}

Acima de tudo, ao Professor Nelson Mannrich, meu orientador. Um verdadeiro orientador. Nenhuma palavra bastará para expressar minha imensa gratidão a esse homem tão humilde e generoso, por tudo que me proporcionou durante o mestrado. De toda forma, registro aqui meu agradecimento especial pela efetiva orientação acadêmica, por fazer questão de discutir cada decisão pertinente ao programa, pelas amizades que surgiram a partir de meu ingresso, pelos encontros que promoveu apenas pelo prazer de fortalecer os laços com e entre seus orientandos, pelos intercâmbios, pela oportunidade de trabalho, pelo aprendizado diário, pela confiança, paciência e afeto, pela leitura cuidadosa de minha dissertação e por respeitar meus pontos de vista divergentes, por vibrar a cada novo resultado alcançado no curso de meus estudos, pelo apoio irrestrito durante a batalha mais dura de minha vida.

Aos orientandos mais antigos do Professor Nelson Mannrich, pela calorosa acolhida ao grupo. Àqueles a mim contemporâneos e aos mais novos, pelo fraternal companheirismo, sobretudo durante cumprimento de créditos, assim como à amizade que levarei para a vida.

Aos membros do GETRAB-USP que participaram dos intercâmbios proporcionados pelo Professor Nelson Mannrich durante meus anos de mestrado: Uruguai (2016), Argentina (2016), Chile (2017), Peru (2017), Colômbia (2018) e México (2018). Foram excelentes fontes de aprendizado, como também de alegria e amizade. Agradeço pelos bons momentos que passamos durante esses anos.

Aos Professores Antoine Jeammaud, Ari Marcelo Solon, Celso Fernandes Campilongo, Elza Antônia Pereira Cunha Boiteux e Ronaldo Porto Macedo Júnior, pelo aprendizado em aulas cursadas ao longo do mestrado.

Aos Professores Estêvão Mallet e Guilherme Guimarães Feliciano, pelas contribuições durante meu exame de qualificação.

Ao companheiro, Marcio, como aos familiares e amigos, por compreenderem minhas ausências ao longo dos últimos três anos e por reconhecerem que as presenças muitas vezes resultaram de grande esforço. 



\section{DEDICATÓRIA}

Primordialmente, à memória de meu amado pai. Ninguém nessa vida teve tanto orgulho de meus passos como ele. Uma explosão de felicidade a cada conquista. Tivemos a chance de festejar juntos meu ingresso ao mestrado. Mas não sua conclusão, porque fui surpreendida com sua partida durante os estudos. Onde quer que esteja, vibra agora por mais esse resultado alcançado por sua querida filha. Sigo aqui atendendo às suas expectativas.

Não posso deixar de mencionar meu companheiro, Marcio. Nunca hesitou em me apoiar. Da decisão de aderir ao processo seletivo, às aflições das últimas etapas, ele cá esteve para segurar minhas mãos.

Devo aqui incluir minha mãe e irmãos. Que aos mais novos sirva de incentivo para valorizar ainda mais a vida acadêmica.

Livia, grata surpresa que floresceu no curso dos estudos, que ainda nada compreende, é para servir de inspiração a você também. Que the desperte o instinto estudioso o quanto antes possível. 



\section{RESUMO}

CEZARIO, Priscila Freire da Silva. Saúde e segurança do teletrabalhador. 274 p. Mestrado - Faculdade de Direito, Universidade de São Paulo, São Paulo, 2019.

O presente estudo é dedicado à análise de questões afetas à saúde e segurança do teletrabalhador, tendo-se em vista a recente regulamentação do teletrabalho, no Brasil, pela Lei $\mathrm{n}^{\mathrm{o}} 13.467 / 2017$. A partir de perspectiva histórica, crítica e devidamente contextualizada, serão identificados os destinatários das novas regras, com passagem pelo teletrabalho transnacional e transregional, assim como será determinada a medida de aplicação de normas regulamentadoras a teletrabalhadores, com ênfase na temática da saúde e segurança. Ainda, será sugerida a revogação da isenção de controle de jornada procedida pela Lei $\mathrm{n}^{\mathrm{o}}$ 13.467/2017, bem como fornecidos parâmetros para que empregadores comprometidos com seus stakeholders pratiquem o que chamamos de autogestão moderada pelo controle, independentemente da mencionada revogação. Por fim, será verificado como o empregador pode promover a fiscalização do exercício seguro das atividades de seus empregados em regime de teletrabalho. Em síntese, o estudo sugere medidas tendentes a efetivar a saúde dos teletrabalhadores em seu sentido mais amplo, ou seja, um completo bem-estar, físico, mental e social.

Palavras-chave: Teletrabalho. Teletrabalhador. Saúde e segurança. Ergonomia. Duração do trabalho. 



\begin{abstract}
CEZARIO, Priscila Freire da Silva. Health and safety of the teleworker. 274 p. Master Faculty of Law, University of São Paulo, São Paulo, 2019.

This study is devoted to the analysis of issues related to the health and safety of teleworkers, considering the recent regulation of telework in Brazil by Law No. 13467/2017. From a historical, critical and contextualized perspective, it will be identified the addressees of the new standards, with passage through transnational and transregional telework, as well as it will be determined the measure of application of Regulatory Norms to teleworkers, with emphasis to the issue of the health and safety. Moreover, it will be suggested the revocation of the exemption of shift control proceeded by Law No. 13467/2017, as well as it will be provided parameters to employers committed with their stakeholders practice what we call self-management moderated by control, regardless of the mentioned revocation. Finally, it will be verified how the employer can promote the inspection of the safe exercise of the activities of its employees within a telework policy. In summary, the study suggests measures tending to effect the health of teleworkers in the broadest sense, that is, a complete well-being, physical, mental and social.
\end{abstract}

Keywords: Telework. Teleworker. Health and safety. Ergonomics. Work duration. 



\section{LISTA DE SIGLAS}

- AET: Análise Ergonômica do Trabalho

- AFT: Auditor Fiscal do Trabalho

- ANAMATRA: Associação Nacional dos Magistrados da Justiça do Trabalho

- ASO: Atestado de Saúde Ocupacional

- CAE: Comissão de Assuntos Econômicos, do Senado Federal

- CAS: Comissão de Assuntos Sociais, do Senado Federal

- CAT: Comunicação de Acidente do Trabalho

- CCJC: Comissão de Constituição e Justiça e de Cidadania, do Senado Federal

- CEEP: European Centre of Entreprises with Public Participation and of Entreprises of General Economic Interest

- CGU: Controladoria Geral da União

- CIPA: Comissão Interna de Prevenção de Acidentes

- CLT: Consolidação das Leis do Trabalho

- CNAE: Classificação Nacional de Atividades Econômicas

- CNJ: Conselho Nacional de Justiça

- CRFB: Constituição da República Federativa do Brasil

- CSB: Central dos Sindicatos Brasileiros

- CSJT: Conselho Superior da Justiça do Trabalho

- CTB: Central dos Trabalhadores e Trabalhadoras do Brasil

- CTPP: Comissão Tripartite Paritária Permanente

- CUT: Central Única dos Trabalhadores

- DORT: Distúrbios Osteomusculares Relacionados ao Trabalho

- EPI: Equipamento de Proteção Individual

- ETUC: European Trade Union Confederation

- EUA: Estados Unidos da América

- FAP: Fator Acidentário de Prevenção

- FENAINFO: Federação Nacional das Empresas de Informática

- FUNDACENTRO: Fundação Jorge Duprat Figueiredo de Segurança e Medicina do Trabalho

- LER: Lesões por Esforços Repetitivos 
- LINDB: Lei de Introdução às Normas do Direito Brasileiro

- NCST: Nova Central Sindical de Trabalhadores

- NR: Norma Regulamentadora

- OIT: Organização Internacional do Trabalho

- OMS: Organização Mundial da Saúde

- PCMSO: Programa de Controle Médico de Saúde Ocupacional

- PIACT: Programa para a Melhoria das Condições e do Ambiente de Trabalho

- PPRA: Programa de Prevenção de Riscos Ambientais

- PSDB: Partido da Social Democracia Brasileira

- PT: Partido dos Trabalhadores

- RGPS: Regime Geral de Previdência Social

- SDI-I: Subseção de Dissídios Individuais I

- SEPROSP: Sindicato das Empresas de Processamento de Dados e Serviços de Informática do Estado de São Paulo

- SESMT: Serviços Especializados em Engenharia de Segurança e em Medicina do Trabalho

- SINDPD: Sindicato dos Empregados em Empresas de Processamentos de Dados, de Serviços de Computação, de Informática e Tecnologia da Informação e dos Trabalhadores em Processamento de Dados, Serviços de Computação, Informática e Tecnologia da Informação do Estado de São Paulo

- SOBRATT: Sociedade Brasileira de Teletrabalho e Teleatividades

- STF: Supremo Tribunal Federal

- TCU: Tribunal de Contas da União

- TIC: Tecnologias da informação e comunicação

- TJSP: Tribunal de Justiça do Estado de São Paulo

- TRT: Tribunal Regional do Trabalho

- TRF4: Tribunal Regional Federal da $4^{\mathrm{a}}$ Região

- TST: Tribunal Superior do Trabalho

- UGT: União Geral dos Trabalhadores

- UEAPME: European Association of Craft, Small and Medium-sized Entreprises

- UNICE: Confederation of European Business 


\section{SUMÁRIO}

INTRODUÇÃO

i. Linha de pesquisa e projeto acadêmico …………………………………....19

ii. Justificativa da escolha e da importância do tema ……………………………....19

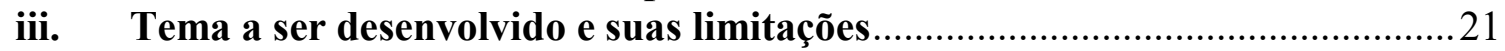

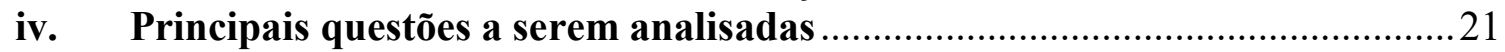

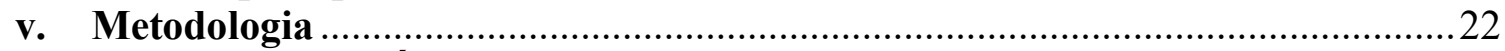

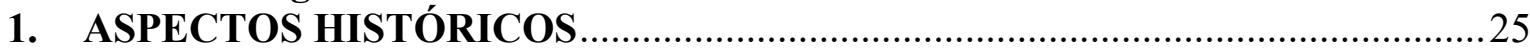

1.1. Transformaçẽes do mundo do trabalho ......................................................2

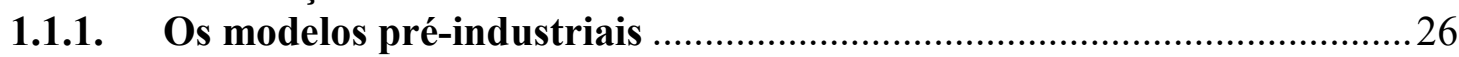

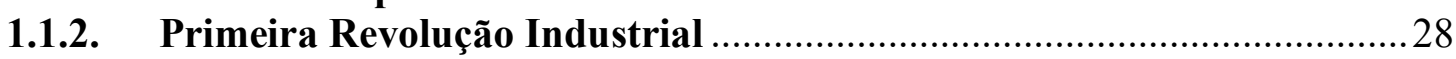

1.1.2.1. A questão social e o surgimento do Direito do Trabalho ....................30

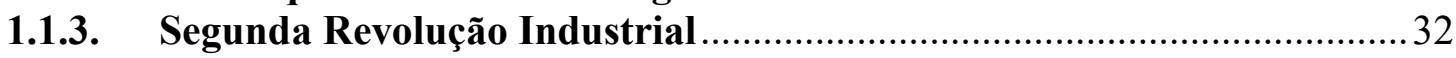

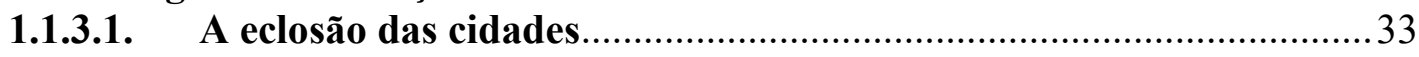

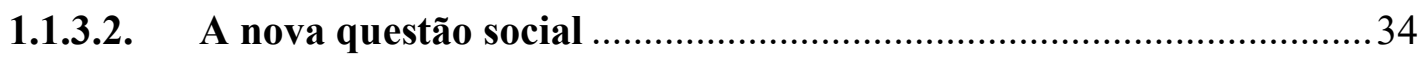

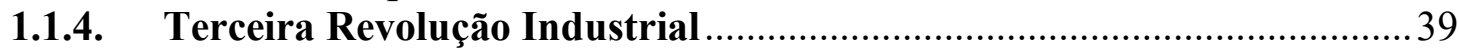

1.1.4.1. Evolução histórica do computador ......................................................39

1.1.4.2. Um novo paradigma organizacional_...................................................4

1.1.4.3. O nascimento de uma nova sociedade ..............................................4 46

1.1.4.4. Uma nova face da questão social .......................................................4

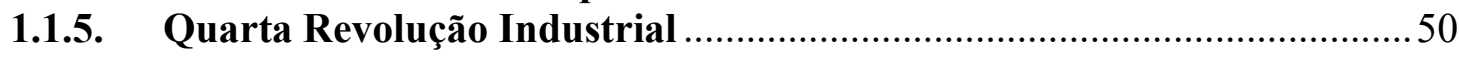

1.2. Transformações dos perfis do empregado e do empregador …………….......55

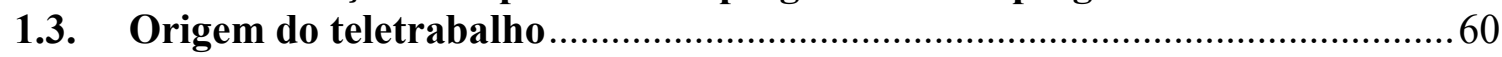

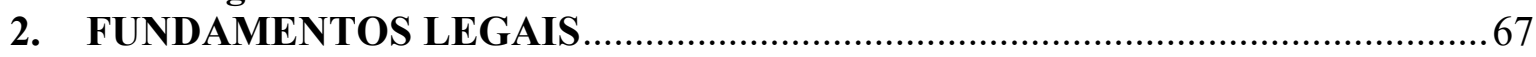

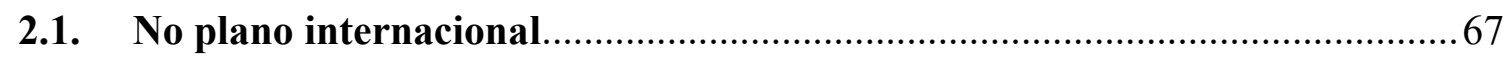

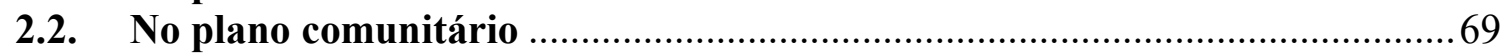

2.3. No plano normativo de alguns países ............................................................. 70

2.4. No plano normativo brasileiro ………………….......................................

2.4.1. Panorama legislativo anterior à Lei $\mathbf{n}^{0}$ 13.467/2017 ............................. 73

2.4.2. Regulamentação do teletrabalho pela Lei ${ }^{0} 13.467 / 2017$, sob o prisma da sociologia jurídica: o direito vivo e a sociedade na perspectiva de Eugen Ehrlich

2.4.3. Os possíveis limites do direito sob a perspectiva do pluralismo jurídico 78

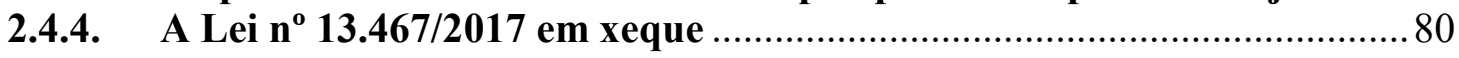

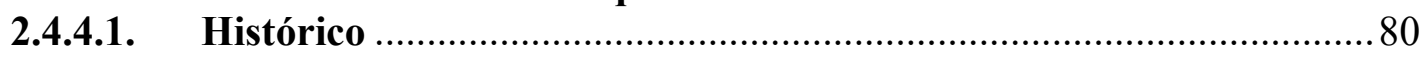

2.4.4.2. Contexto

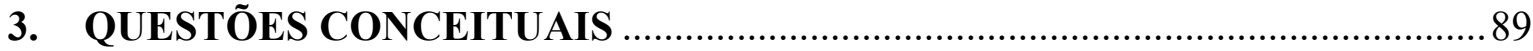

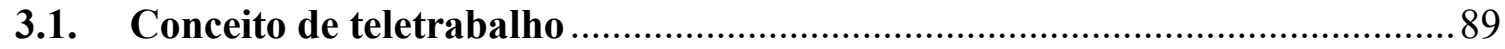

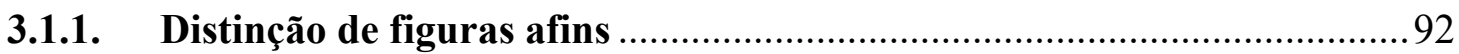

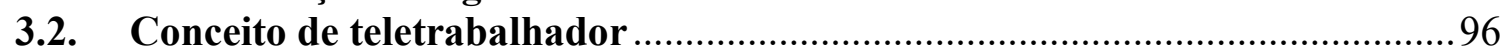

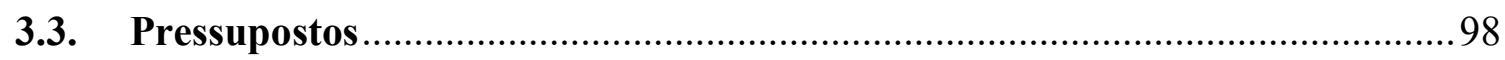

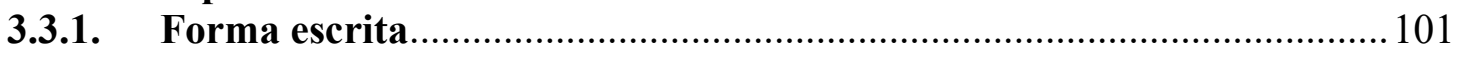

3.3.2. Prestação de serviços no domicílio do empregado ……………………....... 101

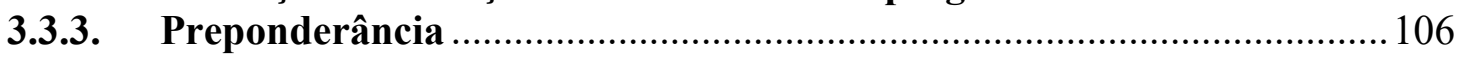

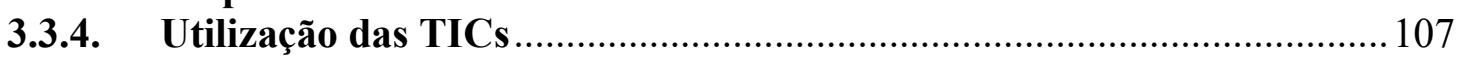

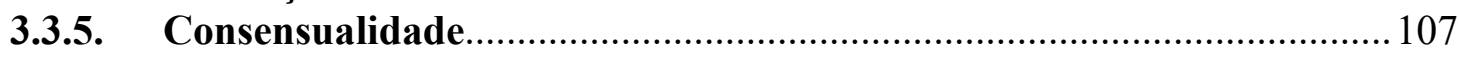

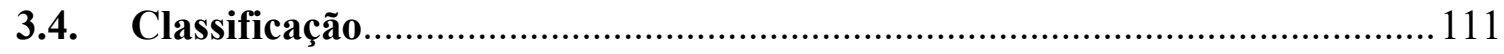

3.4.1. Quanto ao local da prestação de serviços .................................................111

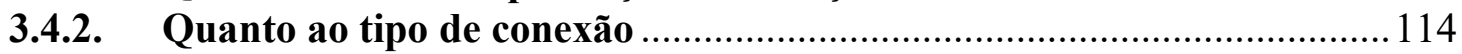


3.4.3. Quanto à alternância entre os regimes de teletrabalho e presencial .....115

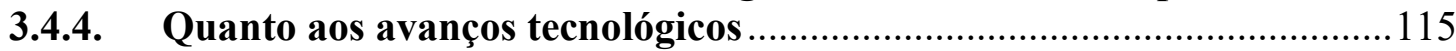

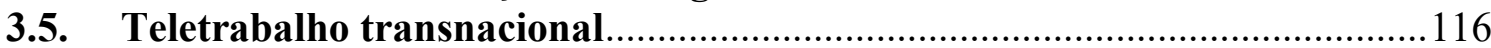

3.5.1. Mecanismos do Direito Internacional Privado para solução de conflitos de leis no espaço

3.5.2. Do primado da lex loci executionis à doutrina dos vínculos mais estreitos

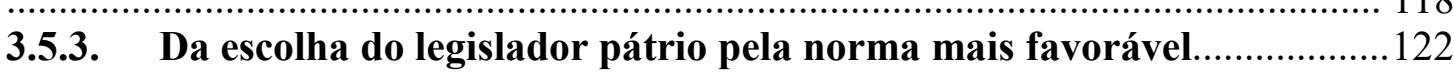

3.5.4. Da autonomia da vontade à subordinação como vetor de segurança jurídica

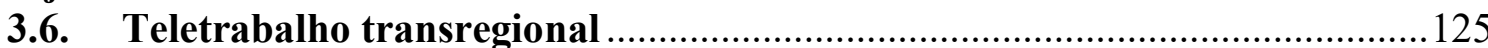

4. SAÚDE E SEGURANÇA NO REGIME DE TELETRABALHO .........................131

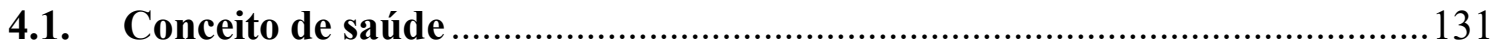

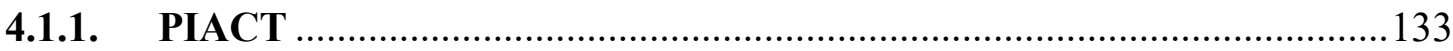

4.1.2. Convenção $n^{\circ} 155$ e Recomendação $n^{\circ} 164$, da OIT, sobre saúde e segurança dos trabalhadores e o meio ambiente de trabalho ..............................134

4.1.3. Convenção $n^{0} 177$ e Recomendação $n^{0} 184$, da OIT, sobre trabalho em domicílio

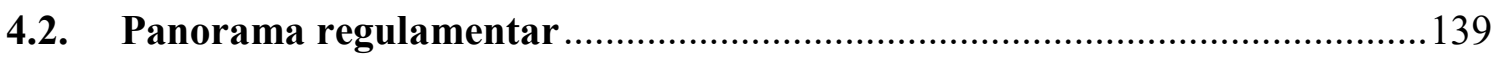

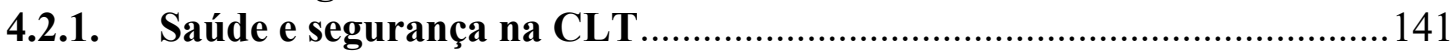

4.2.2. NRs incidentes sobre o regime de teletrabalho ..................................145

4.2.2.1. Órgãos internos voltados à preservação da saúde ...........................146

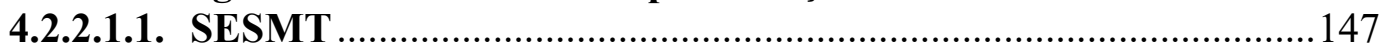

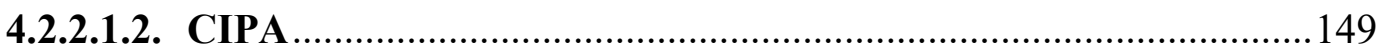

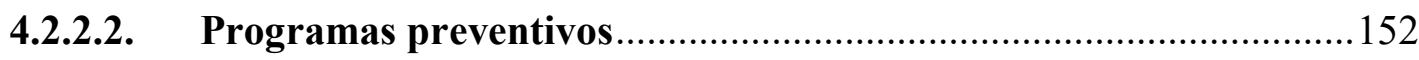

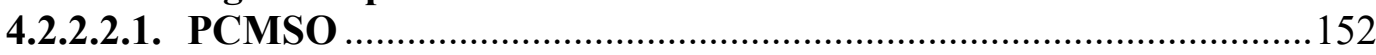

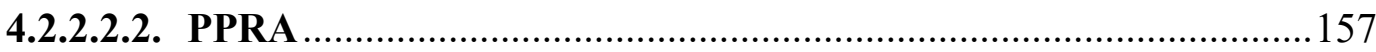

4.2.2.2.3. Aprimoramento de programas preventivos por meio da negociação

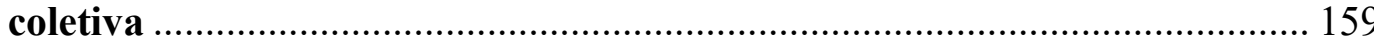

4.2.2.2.4. O novo artigo 75-E, da CLT, em face do dever geral de prevenção

162

4.2.2.3. Aplicação dos regimes jurídicos da insalubridade e periculosidade ao

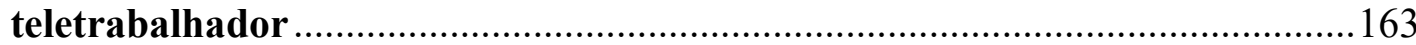

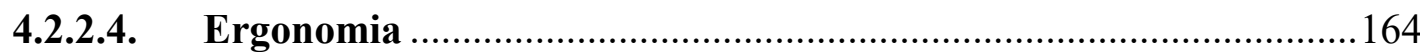

4.2.2.4.1. Aplicabilidade da NR-17 a teletrabalhadores ............................171

4.2.2.4.2. Deveres gerais de informação e formação …................................ 172

4.2.2.4.3. Riscos cobertos pela NR-17 .................................................... 175

4.2.2.4.4. Responsabilidade pelos custos de infraestrutura necessária e

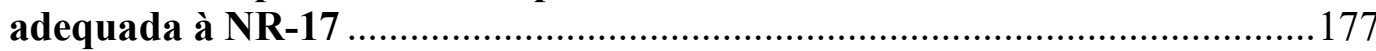

4.2.2.4.5. Medidas para incentivar o cumprimento da NR-17 ...................178

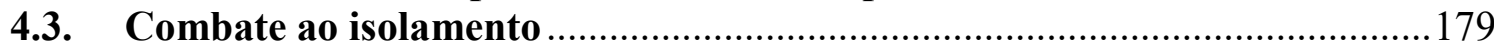

5. RELAÇÕES ENTRE DURAÇÃO DO TRABALHO E SAÚDE ..........................185

5.1. Preservação da saúde do teletrabalhador por meio da limitação da duração do

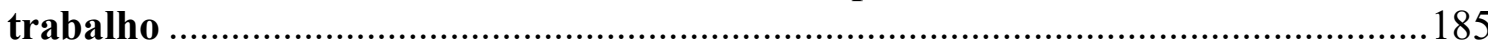

5.2. Críticas ao tratamento conferido pela Lei $n^{0} 13.467 / 2017$ à jornada do

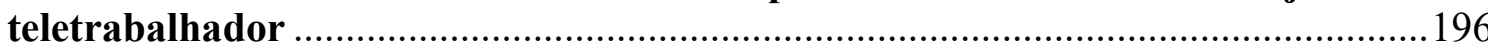

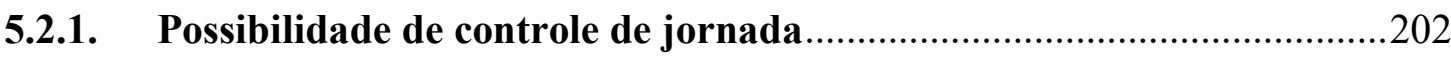

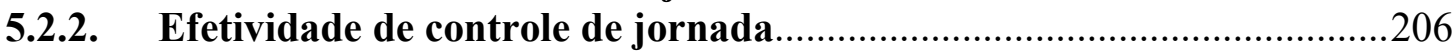

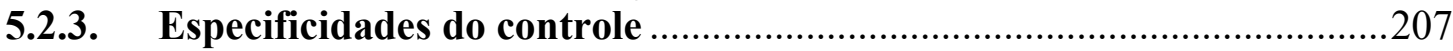

5.2.4. A caminho da autogestão moderada pelo controle ..............................213 
5.3. Direito à desconexão

216

6. FISCALIZAÇÃO DAS CONDIÇÕES DE TRABALHO DO

TELETRABALHADOR: A INVIOLABILIDADE DE DOMICÍLIO EM XEQUE 223

6.1. O poder fiscalizatório do empregador e a inspeção do trabalho ..................223

6.1.1. Caráter absoluto dos direitos fundamentais à inviolabilidade de domicílio

e à privacidade.

225

6.1.2. Caráter relativo dos direitos fundamentais à inviolabilidade de domicílio

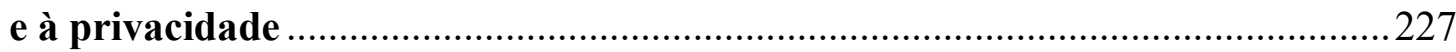

6.1.3. Da fuga fiscalizatória à proporcionalidade .....................................232

6.2. Dever geral de cooperação

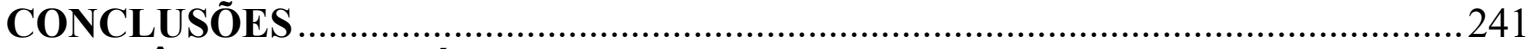

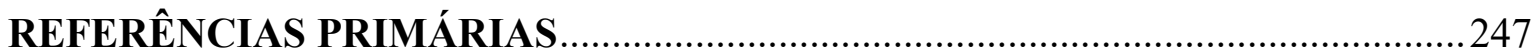

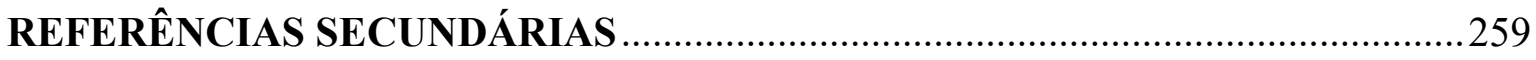





\section{INTRODUÇÃO}

\section{i. Linha de pesquisa e projeto acadêmico}

O presente estudo visa a examinar questões afetas à saúde e segurança do teletrabalhador. O trabalho insere-se na linha de pesquisa "direitos sociais no contexto dos direitos humanos", da área de concentração Direito do Trabalho e da Seguridade Social (DTBS), compondo o projeto acadêmico "a eficiência dos institutos, normas e princípios de direito interno, comunitário e internacional do trabalho e a efetivação dos direitos humanos".

\section{ii. Justificativa da escolha e da importância do tema}

Nas últimas décadas, a sociedade presenciou vertiginosa evolução da tecnologia. Ao lado do desenvolvimento tecnológico, os centros urbanos ficaram superlotados, os problemas ambientais cresceram e a saúde mental de trabalhadores foi afetada. Paralelamente, os direitos fundamentais da pessoa humana foram aprimorados. A Constituição Cidadã, de 1988, é prova desse aprimoramento.

Os paradoxos retratados no parágrafo precedente despertam a necessidade de uma revisita ao modelo tradicional de prestação de serviços a empregador, notadamente no que toca ao local a partir do qual as atividades são desenvolvidas. Os meios tecnológicos contemporâneos não justificam a concentração de profissionais que os têm como ferramentas de trabalho em escritórios profissionais. Computadores, smartphones e afins permitem a arquitetos, advogados, engenheiros, jornalistas, publicitários, tradutores, vendedores, etc., prestarem serviços aos seus empregadores a partir de seus próprios domicílios.

A adesão de empregados e empregadores ao teletrabalho em domicílio reduziria o impacto ambiental causado pelos veículos automotores desses empregados que, diariamente, deixam seus lares para permanecer tempo considerável de seu dia apenas dentro de seus automóveis, sem nada usufruir ou produzir, além de poluição e estresse. Os empregados que fazem uso dos sistemas públicos de transporte, como aqueles que adotam o veículo particular com o propósito de se deslocar de casa para o trabalho, e do trabalho para casa, também perdem seu precioso tempo com locomoção. Aliás, considerada a ineficiência dos meios públicos de transporte, as consequências do excessivo tempo perdido com deslocamento são ainda mais danosas a esse grupo de trabalhadores. 
Considerada a atual conjuntura do tráfego urbano e tendo em mente a incessante busca, derivada de mandamento constitucional, da melhoria da condição social dos trabalhadores, o empregado, em função de modelo organizacional ultrapassado, não pode permanecer refém de longos períodos de deslocamento. Não pode suportar sozinho os ônus dos congestionamentos.

Por outro lado, não se pretende impor ao empregador a assunção de tal encargo, passando a remunerar o tempo de locomoção de seus empregados. O teletrabalho em domicílio representa solução razoável para que nenhum dos protagonistas da relação empregatícia sofra as consequências danosas dos congestionamentos que assolam os grandes centros urbanos. A modalidade de teletrabalho em domicílio é privilegiada no presente estudo, em detrimento de outras, por ser aquela que melhor atende à necessidade de eliminar o período de deslocamento da rotina dos teletrabalhadores.

A princípio, o teletrabalho em domicílio imporia ao empregador os custos com deslocamentos de informações, assim como com a infraestrutura tecnológica e ergonômica adequada ao exercício das atividades do empregado. Em contrapartida, poderia passar suas instalações físicas centralizadas para escritórios menores, reservados às excepcionais situações em que os empregados em regime de teletrabalho em domicílio necessitassem se encontrar com seu superior hierárquico, colegas de trabalho e, ou, clientes. Ainda, o empregador passaria a contar com uma mão de obra mais produtiva, em consequência da satisfação proporcionada por atividades pessoais que passariam a ser exercidas em lugar do tempo expendido com deslocamento.

Há diversos aspectos do teletrabalho em domicílio a serem explorados do ponto de vista acadêmico. A opção pelo tema da saúde e segurança deriva da natureza instigante de tal modalidade. O regime desafia a conciliar direitos fundamentais do empregado, de inviolabilidade de domicílio e privacidade, com o poder diretivo do empregador, mais precisamente no que toca à fiscalização. Se na relação de trabalho típica o empregador tem obrigação irrestrita de zelar pela saúde e segurança de seus empregados, no teletrabalho em domicílio sua atuação é naturalmente mais limitada. Afinal, em seu domicílio, o empregado não está sujeito à permanente vigilância de membro da CIPA, ou de responsável análogo, e, portanto, não tem ninguém para lhe advertir a respeito das posturas e demais condições de trabalho adequadas.

A opção pelo tema da saúde e segurança decorre, ainda, do tratamento conferido à matéria pela Lei $n^{\circ} 13.467 / 2017$, da escassez de doutrina dedicada a esse específico aspecto 
do regime e de nossa preocupação com a qualidade de vida dos trabalhadores, inserida em um projeto maior de busca da felicidade.

\section{iii. Tema a ser desenvolvido e suas limitações}

Tendo em vista a possibilidade de o teletrabalho ser praticado por empregado da iniciativa privada e prestador de serviços autônomo, assim como por servidor ou empregado público, esclarece-se que o presente estudo se limita ao teletrabalhador empregado, mesmo porque a regulamentação do regime pela Lei $n^{0}$ 13.467/2017 vincula somente esse contingente de trabalhadores.

Como será visto por ocasião da análise de seus pressupostos, o teletrabalho é marcado pelo uso intensivo das TIC como parte de uma rotina. O destaque é realizado para registrar que o presente estudo não aborda os regimes que emergem de novas formas de organização do trabalho. As TIC, no teletrabalho, são imprescindíveis à execução da atividade contratada, ao passo que, no trabalho por demanda via plataformas digitais, servem apenas para promover a interface entre prestador e tomador de serviço.

Ainda, apesar de o regime de teletrabalho, em tese, poder ser praticado a partir dos mais variados locais, como telecentros, telecottages e espaços de coworking, o presente estudo cuida do teletrabalho realizado a partir do domicílio do teletrabalhador. Diante da centralidade do domicílio para o presente estudo, esclarece-se que aqui não se analisa o trabalho doméstico. Outro aspecto não enfrentado, apesar de se referir a responsabilidades do empregador em tema de saúde e segurança, é a natureza da responsabilidade em caso de ocorrência de acidente ou eclosão de doença.

\section{iv. Principais questões a serem analisadas}

As principais questões a serem analisadas nessa pesquisa derivam de dispositivos inseridos à CLT pela Lei no 13.467/2017. Iniciando pelo artigo 75-E, verifica-se que seu caput impõe ao empregador o dever de instruir o teletrabalhador quanto aos cuidados a serem tomados para evitar doenças e acidentes de trabalho. Já o parágrafo único impõe ao teletrabalhador o dever de se comprometer a seguir as instruções fornecidas pelo empregador mediante firma de termo de responsabilidade. Será investigado, assim, o que significa instruir o teletrabalhador, bem como se a instrução, pelo empregador, e assinatura de termo 
de responsabilidade, pelo teletrabalhador, seria o suficiente para isentar o empregador de obrigações em matéria de saúde e segurança.

Já o parágrafo único, do artigo 611-B, dispõe que "[r]egras sobre duração do trabalho e intervalos não são consideradas como normas de saúde, higiene e segurança do trabalho". Voltando-se a presente pesquisa à análise de questões afetas à saúde e segurança do teletrabalhador, será investigado se as regras sobre duração do trabalho de fato não são consideradas como normas de saúde, higiene e segurança do trabalho. Concluindo-se a partir de vasta doutrina pela inadequação do dispositivo em referência, será investigado se o legislador agiu com acerto ao afastar de teletrabalhadores a aplicação de regras alusivas à duração do trabalho.

\section{v. Metodologia}

As indagações acima levantadas serão investigadas a partir do método de pesquisa dedutivo, baseado tanto em doutrina clássica quanto em autores especializados, assim como em legislação estrangeira. A pesquisa será conduzida em seis capítulos.

No primeiro capítulo, construído a partir de vasta doutrina, com destaque para obras de Domenico De Masi, Jeremy Rifkin e Manuel Castells, serão lançadas as bases históricas que fundamentam as conclusões extraídas ao final do estudo. Serão examinadas as transformações do mundo do trabalho, passando por modelos pré-industriais e Revoluções Industriais, com exame crítico de cada uma das questões sociais a elas inerentes, destacandose os impactos do desemprego estrutural resultante da automatização. Nesse compasso, serão abordados analiticamente os objetivos perseguidos pela comunidade empresarial com cada uma das Revoluções Industriais, passando pelo papel do Estado na preservação da coesão social. Na sequência, serão analisadas as transformações dos perfis do empregado e do empregador, para ao final se discorrer sobre a origem do teletrabalho, fruto da Terceira Revolução Industrial e das políticas de flexibilização nascidas na Terceira Revolução.

No segundo capítulo, serão examinados os fundamentos legais do teletrabalho nos planos internacional, comunitário, de alguns países estrangeiros e no plano normativo brasileiro. No plano normativo de países estrangeiros, será mencionada apenas a regulamentação de base para os demais capítulos, ou seja, aquela com a qual tivemos contato no curso da pesquisa, sem a pretensão de compor um rol exaustivo dos países que regulamentaram o teletrabalho. A seção passará pela Argentina, Colômbia, Costa Rica, Espanha, EUA, França, Hungria, Itália, Peru, Portugal e Romênia. Foram adotadas como 
ponto de partida do levantamento bibliográfico as legislações portuguesa, espanhola, francesa e italiana, visto que, segundo Nelson Mannrich (2013: 566), o Direito do Trabalho pátrio é baseado no modelo de relações trabalhistas de tais regulamentações, "importante referência para nós".

$\mathrm{Na}$ seção reservada ao plano normativo brasileiro, será examinado o panorama legislativo anterior à regulamentação do teletrabalho pela Lei ${ }^{\circ}$ 13.467/2017, a ser analisada sob a perspectiva da sociologia jurídica. Para tanto, será enfrentada a doutrina de Eugen Ehrlich, eleito em razão do contato que tivemos com sua teoria na disciplina "Ehrlich, Kelsen e Luhmann: Três Conceitos de Direito", ministrada de 11/08/2017 a 23/11/2017, pelo Professor Celso Fernandes Campilongo. Ainda em razão do contato proporcionado pela disciplina do Professor Campilongo, a análise sociológica visitará a doutrina de Rafaelle De Giorgi e Gunther Teubner. A seção será também pautada em exame dos relatórios legislativos que deram origem à regulamentação do teletrabalho pelo ordenamento jurídico pátrio. Estratégias para incentivar o teletrabalho serão mencionadas no final do capítulo.

No terceiro capítulo, será examinado o conceito de teletrabalho, distinguindo-o de figuras afins, como também o conceito de teletrabalhador. Na sequência, serão analisados os pressupostos do teletrabalho, para em seguida se passar para a classificação providenciada pela doutrina. Em seguida, será exibido um panorama sobre o Direito Internacional Privado, com vistas a definir o direito aplicável sobre o teletrabalho transnacional. A seção é baseada, predominantemente, em obra de Antonio Galvão Peres. Logo após, em seção dedicada ao teletrabalho transregional, serão tecidas considerações a respeito da norma coletiva aplicável quando o domicílio do teletrabalhador se situar em base territorial distinta do estabelecimento do empregador ao qual ele estiver vinculado por um elo de subordinação.

No quarto capítulo, serão analisados o conceito de saúde, seu panorama regulamentar e a questão do isolamento. Serão examinadas normas regulamentadoras envolvendo SESMT, CIPA, PCMSO, PPRA, insalubridade, periculosidade e ergonomia, assim como a medida de sua aplicação a teletrabalhadores, com maior destaque para a temática da ergonomia. No capítulo em apreço serão abordadas a importância da análise do perfil do teletrabalhador, como também da formação desse profissional para trabalhar a partir de seu domicílio. Ao final do capítulo, será verificado se o teletrabalho realmente provoca o isolamento do teletrabalhador, como também serão examinadas medidas tendentes a combater esse risco.

No quinto capítulo, serão analisadas as relações entre duração do trabalho e saúde. Em primeiro lugar, será posta em xeque a prescrição jurídica contida no parágrafo único, do 
novo artigo 611-B, da CLT, que nega às regras atinentes à duração do trabalho o caráter de normas de saúde e segurança do trabalho. Em segundo lugar, serão relacionadas críticas ao tratamento conferido pela Lei $n^{\circ} 13.467 / 2017$ à jornada do teletrabalhador. Será discutida a possibilidade de controle de jornada, como analisadas as consequências da efetividade de controle e especificidades a ele inerentes, incluindo exame da lei de proteção de dados recentemente incorporada ao ordenamento jurídico pátrio, para em seguida marcar a posição assumida pela autora. Ao final do capítulo, será discutido o direito à desconexão, com referência ao dano existencial.

No sexto capítulo, a possibilidade de fiscalizar as condições de trabalho do teletrabalhador, tanto pelo empregador quanto por agentes da inspeção do trabalho, será aferida a partir do princípio da inviolabilidade de domicílio. Duas correntes serão discutidas, inclusive sob a ótica da regra da proporcionalidade, com destaque da posição assumida pela autora ao final. 


\section{CONCLUSÕES}

O teletrabalho é fruto da Terceira Revolução Industrial, quando surgidas novas formas de organização do trabalho, por força da demanda de flexibilização derivada da transformação do paradigma operacional ocorrida em tal momento histórico. Deve ser incentivado porque salutar para a sociedade, para o empregador e, sobretudo, para a pessoa do teletrabalhador. Esse incentivo deve provir de políticas fiscais, não pela via da precarização promovida pela Lei $\mathrm{n}^{\mathrm{o}} 13.467 / 2017$, mesmo porque discute-se se a onda flexibilizatória em curso desde a década de 1970 de fato veio para concretizar projeto iniciado no curso da Primeira Revolução Industrial, de substituir a força de trabalho humano, tanto mais quanto possível, pela força das máquinas. Vale dizer, pouco importa se rígida ou flexível a regulamentação do teletrabalho. O projeto de automatização é irreversível.

A nosso ver, as medidas propostas no presente estudo para efetivar a saúde dos trabalhadores em seu sentido mais amplo são simples. Aos empregadores compete fornecer condições para que empregados e seus representantes exerçam seu dever de cooperação, precisamente por meio do reconhecimento de direitos de informação, consulta e formação. Aos empregados compete cumprir as instruções fornecidas pelo empregador e colaborar com a empresa quanto à aplicação das normas de saúde e segurança. Aos sindicatos, por meio da negociação coletiva, aprimorar em favor dos teletrabalhadores o patamar mínimo contido em leis, normas regulamentadoras, entre outras fontes heterônomas. À autoridade competente em matéria de saúde e segurança do trabalho, redigir cartilha orientadora e processo de certificação de competências para o teletrabalho, similar ao regime praticado na Argentina, sem prejuízo da fiscalização.

Em relação à indagação formulada na introdução a respeito de obrigações do empregador em face do caput e parágrafo único do novo artigo 75-E, da CLT, conclui-se que sua responsabilidade para com a saúde e segurança de seus teletrabalhadores não se esgota com a instrução e termo de responsabilidade de que tratam os dispositivos. SESMT e CIPA devem participar ativamente da política de teletrabalho desenvolvida pelo empregador, assim como teletrabalhadores devem ser adicionados à base de cálculo relativa à composição de tais órgãos, assegurando-se a teletrabalhadores a possibilidade de participar de processo de eleição de representante dos trabalhadores na CIPA.

Do mesmo modo, teletrabalhadores devem se sujeitar aos exames médicos obrigatórios concebidos pelo PCMSO, com destaque para o de mudança de função, tanto ao 
passar para o regime de teletrabalho quanto ao regressar ao regime típico, devendo-se ainda enfatizar a necessidade de sua periodicidade ser reduzida a seis meses. Os exames podem ser realizados por médico da localidade em que situado o respectivo domicílio, contanto que sem custos ao empregado e que ouvido o SESMT responsável pelo estabelecimento ao qual subordinado. Sem prejuízo de avaliação de desempenho a ser conduzida pelo respectivo gestor, a avaliação médica deve visar a identificar a aptidão do trabalhador para ingressar no regime de teletrabalho ou nele permanecer. De fato, riscos inerentes ao teletrabalho podem ser evitados mediante inclusão de empregados com perfil adequado. As políticas de teletrabalho concebidas pelo Manual argentino de Boas Práticas no Teletrabalho, como pela Prefeitura de Los Angeles, na Califórnia, fornecem interessantes subsídios para identificação do perfil adequado ao regime.

A estação de teletrabalhadores não deve ser objeto do PPRA, mas em suas ações e princípios deve ser baseada a AET, a ser desenvolvida com base nas características do mobiliário e dos equipamentos de trabalho a serem utilizados por teletrabalhadores tais como dispostas in loco. Em função de sua responsabilidade social, empregadores devem orientar seus empregados quanto aos limites de exposição a agentes insalubres, o que não significa assumir ônus, como fornecer EPI ou pagar adicional, relacionados à exposição derivada de circunstâncias alheias ao seu poder diretivo. Não obstante, mediante complementação da NR-17, recomendada neste estudo, empregadores devem fornecer extintor portátil contra incêndio e caixa de primeiros socorros a teletrabalhadores.

A NR-17 contempla inúmeras disposições tendentes a promover a adaptação das condições de trabalho às características psicofisiológicas de trabalhadores em geral. Com exceção da jornada diferenciada de seis horas, destinada à atividade de operação de teleatendimento/telemarketing, assim como dos intervalos diferenciados e controle do tempo de trabalho, teletrabalhadores em geral devem ser beneficiados pelas disposições da NR-17, em especial pelo seu anexo II, examinadas nesse estudo. Além da similitude entre as estações de trabalho do teletrabalhador e do operador de teleatendimento/telemarketing, a aplicação das disposições em referência ao teletrabalhador se justifica por promover o exercício ergonomicamente adequado das atividades em regime de teletrabalho, como por versar sobre mecanismos para monitoramento da produtividade e capacitação dos empregados, além de relacionar a necessidade de o PCMSO reconhecer e registrar os riscos identificados na AET.

O cumprimento da NR-17 é fundamental para prevenir LER/DORT, entre outras moléstias de efeito retardado associadas ao uso de computador, como glaucoma, doenças de coluna, perda de audição, além de estresse emocional. A NR-17 reflete preocupação também 
com o risco de obesidade, que pode ser combatido mediante incentivos para teletrabalhadores praticarem atividade física e se alimentarem de forma saudável. Custos de infraestrutura necessária e adequada à NR-17 não podem ser transferidos ao empregado. Porém, se o empregado, por ocasião do início da prestação de serviços em regime de teletrabalho, já dispuser em sua residência dessa infraestrutura, as partes poderão acordar a isenção de custos do empregador.

Os riscos contemplados pela NR-17 não constituem peculiaridade do regime de teletrabalho, situando-se em diferente plano o fator isolamento. O teletrabalho não necessariamente promove isolamento, porque a socialização fora do ambiente profissional é mais provável. Não obstante, reclama-se a socialização de questões relacionadas ao trabalho, que pode ser promovida mediante fixação de número mínimo de dias para prestação de serviços nas dependências do empregador, além de incentivos para uso de redes sociais ou mesmo de robôs móveis de telepresença, respeitando-se a preferência de trabalhadores mais introspectivos por não utilizar tais ferramentas.

Quanto à indagação endereçada na introdução envolvendo o significado da expressão instruir, presente no caput, do novo artigo 75-E, da CLT, conclui-se que teletrabalhadores devem ser treinados com vistas à melhoria de sua produtividade e nível de qualificação. A formação deve servir também para preparar o teletrabalhador a lidar com uma estrutura mais enxuta, administrar de forma responsável a liberdade de gestão de seu tempo de trabalho, treinar seus familiares e amigos para que compreendam que o período dedicado ao trabalho em regime de teletrabalho é um período normal de trabalho e compreender que existem regras a serem respeitadas no trabalho desenvolvido em seu domicílio, como ocorre nas instalações do empregador.

A formação deve ainda versar sobre ergonomia, cumprimento das normas de saúde e segurança, questões decorrentes da mudança de horário de trabalho e do isolamento de colegas de trabalho, sem olvidar de técnicas anti-estresse. Deve ser realizada a cada seis meses, com duração de pelo menos quatro horas, contínuas ou não, podendo ser presencial ou à distância, via palestras ou cursos. Gerentes de teletrabalhadores devem ser treinados para mantê-los produtivos, assim como para incutir a cultura do regime em trabalhadores não qualificados para o regime, com vistas a desenvolver suas habilidades para trabalhar em casa.

No que diz respeito à indagação contida na introdução acerca do acerto do legislador ao afastar de teletrabalhadores a aplicação de regras alusivas à duração do trabalho, concluise em sentido negativo. Em lugar da isenção de jornada inserida no inciso III, do artigo 62, 
da CLT, cuja revogação recomendamos, propomos praticar o que denominamos autogestão moderada pelo controle, concretizada por meio de login e logoff. Nesse sistema, a ser combinado com banco de horas, prestigia-se a liberdade do teletrabalhador para administrar seu tempo de trabalho, ao mesmo tempo em que se preserva o limite de quarenta e quatro horas semanais fixado pela Constituição.

A nosso ver, independentemente da revogação do novo inciso III, do artigo 62, da CLT, empregadores preocupados com a qualidade de vida de seus empregados podem praticar a autogestão moderada pelo controle, observados os ditames da Lei $n^{\circ}$ 13.709/2018, sobre proteção de dados pessoais, precisamente no que toca ao consentimento do empregado. A propósito, o dispositivo, atinente à duração do trabalho, foi examinado nesse estudo, sobre saúde e segurança, porque verificada aqui a inadequação da afirmação inserida no parágrafo único, do artigo 611-B, da CLT, de que "[r] egras sobre duração do trabalho e intervalos não são consideradas como normas de saúde, higiene e segurança do trabalho". Responde-se, assim, à indagação presente na introdução quanto à natureza das regras sobre duração do trabalho.

As providências até aqui relacionadas não limitam as obrigações do empregador em matéria de saúde e segurança do teletrabalhador. São complementadas pela fiscalização das condições de trabalho, inevitável por força de tratados internacionais ratificados pelo Brasil. Pode ser realizada mediante prévio aviso e anuência do empregado, devendo-se adicionar a esses pressupostos o acompanhamento do responsável pela fiscalização pelo empregado ou por alguém de sua família por este designado, como prevê a Lei complementar no 150/2015, a ser aplicada por analogia.

Para o caso de o empregado expressamente recusar a fiscalização in loco, sob o prisma de seu dever geral de cooperação, deve-se permitir a utilização de checklist para ele próprio aferir a conformidade de suas condições de trabalho a parâmetros mínimos de saúde e segurança, obviamente mediante orientações dos responsáveis pelo cumprimento das normas de saúde e segurança na empresa.

Em qualquer caso, a forma mediante a qual o exercício seguro das atividades será fiscalizado, se direta, presencialmente, ou indireta, via checklist, deve ser relacionada no contrato de trabalho ou no aditivo contratual para implementação do regime. Por força da Convenção ${ }^{\circ}$ 81, da, OIT, ratificada pelo Brasil, o checklist não será oponível aos agentes da inspeção.

As medidas aqui propostas serão consideradas rígidas a depender da lente a partir da qual sejam analisadas. A nosso ver, a nova regulamentação precariza a condição de trabalho 
do teletrabalhador, porque piorou as condições de trabalho do teletrabalhador, em comparação com o empregado típico ou com o próprio teletrabalhador no período préreforma. Isso sobretudo diante da tentativa de isentar o empregador de qualquer responsabilidade em matéria de saúde e segurança do teletrabalhador, inclusive por causa da isenção de jornada sem qualquer tipo de ressalva, equiparando-se teletrabalhadores a detentores de cargo de confiança. O regime não é privilégio de altos empregados ou de empregados revestidos de atividades intelectuais, considerados empregados de colarinho branco. Pode ser praticado também por trabalhadores considerados de colarinho azul, incumbidos de inserir dados em sistema ou de qualquer outra atividade repetitiva e desprovida de manifestação criativa e, ou, intelectual. Nesse compasso, pensamos que somente as providências aqui sugeridas podem de fato promover um completo bem-estar, físico, mental e social aos teletrabalhadores em geral. 



\section{REFERÊNCIAS PRIMÁRIAS}

ARGENTINA. Ministerio de Trabajo, Empleo y Seguridad Social. Presidencia de la Nación. Manual de buenas prácticas de salud y seguridad en el teletrabajo. 2010. Disponível em: $\quad<$ https://www.argentina.gob.ar/sites/default/files/100924_manual-buenaspracticas.pdf $>$. Acesso em: 01/04/2018.

. Ministerio de Trabajo, Empleo y Seguridad Social. Resolución 595/2013. Créase el Programa de Promoción del Empleo en Teletrabajo. Objetivos. Disponível em: $<$ http://servicios.infoleg.gob.ar/infolegInternet/anexos/215000-

219999/217070/norma.htm>. Acesso em: 08/04/2018.

Superintendencia de Riesgos del Trabajo. Resolución 1.552/2012. Teletrabajo. Definición. Condiciones. Disponível em: $<\mathrm{http}$ //servicios.infoleg.gob.ar/infolegInternet/anexos/200000-

204999/204726/norma.htm>. Acesso em: 08/04/2018.

Assembleia Geral das Nações Unidas. Declaração Universal dos Direitos Humanos. Adotada e proclamada em 10 de dezembro 1948. Disponível em: $<$ https://www.unicef.org/brazil/pt/resources_10133.htm>. Acesso em: 16/10/2018.

. CÂMARA DOS DEPUTADOS. Projeto de Lei no 4.505, de 2008. Regulamenta o

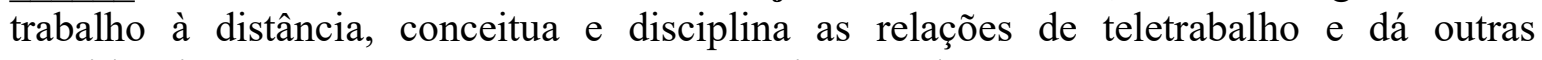
providências. Disponível em: $<$ http://www.camara.gov.br/proposicoesWeb/fichadetramitacao?idProposicao $=420890>$ Ac esso em: 08/07/2017.

CÂMARA DOS DEPUTADOS. Projeto de Lei n⿳0 6.038, de 2016. Acrescenta o artigo 72-A à Consolidação das Leis do Trabalho (CLT), para dispor sobre o direito à desconexão do trabalho. Disponível em: $<$ http://www.camara.gov.br/proposicoesWeb/fichadetramitacao?idProposicao=2095458>. Acesso em: 27/05/2018.

CÂMARA DOS DEPUTADOS. Projeto de Lei $\mathbf{n}^{\mathbf{0}} \mathbf{6 . 7 8 7}$, de 2016. Altera a Consolidação das Leis do Trabalho (CLT), aprovada pelo Decreto-Lei $\mathrm{n}^{\mathrm{o}} 5.452$, de $1^{\mathrm{o}}$ de maio de 1943, e as Leis $n^{\circ}$ s 6.019, de 3 de janeiro de 1974, 8.036, de 11 de maio de 1990, e 8.212, de 24 de julho de 1991, a fim de adequar a legislação às novas relações de trabalho. Disponível em: $<$ http://www.camara.gov.br/proposicoesWeb/fichadetramitacao?idProposicao=2122076>. Acesso em: 08/07/2017.

CÂMARA DOS DEPUTADOS. COMISSÃO ESPECIAL DESTINADA A PROFERIR PARECER AO PROJETO DE LEI N ${ }^{\circ}$ 6.787, DE 2016, DO PODER EXECUTIVO, QUE “ALTERA O DECRETO-LEI N ${ }^{\circ}$ 5.452, DE $1^{\circ}$ DE MAIO DE 1943 CONSOLIDAÇÃO DAS LEIS DO TRABALHO, E A LEI N 6.019, DE 3 DE JANEIRO DE 1974, PARA DISPOR SOBRE ELEIÇÕES DE REPRESENTANTES DOS TRABALHADORES NO LOCAL DE TRABALHO E SOBRE TRABALHO TEMPORÁRIO, E DÁ OUTRAS PROVIDÊNCIAS." Relatório do Deputado Rogério Marinho. Brasília, 12 abr. 2017. Disponível em: 
$<$ http://www.camara.gov.br/proposicoesWeb/prop_mostrarintegra?codteor $=1544961 \&$ filen ame $=$ Tramitacao-PL+6787/2016> . Acesso em: 06/05/2018.

. CONSELHO NACIONAL DE JUSTIÇA. Resolução n⿳2 227, de 15 de junho de 2016. Regulamenta o teletrabalho no âmbito do Poder Judiciário e dá outras providências. Disponível em: $<$ http://www.cnj.jus.br/images/atos_normativos/resolucao/resolucao_227_15062016_1706 2016161058.pdf $>$. Acesso em: 09/07/2017.

. CONSELHO SUPERIOR DA JUSTIÇA DO TRABALHO. Resolução n⿳ $\mathbf{1 5 1}$, de 29 de maio de 2015. Incorpora a modalidade de teletrabalho às práticas institucionais dos órgãos do Judiciário do Trabalho de primeiro e segundo graus, de forma facultativa, observada a legislação vigente. Disponível em: $<$ https://juslaboris.tst.jus.br/bitstream/handle/1939/63630/2015_res0151_csjt.pdf?sequence $=1 \&$ isAllowed $=\mathrm{y}>$. Acesso em: 09/07/2017.

Constituição da República Federativa do Brasil de 1988. Disponível em:

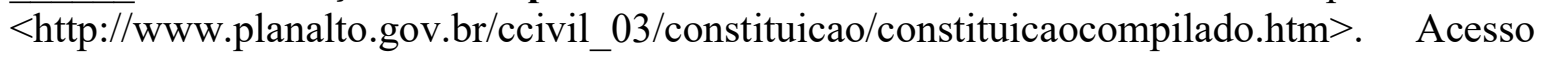
em: 08/07/2017.

. Decreto $n^{0}$ 18.871, de 13 de agosto de 1929. Promulga a Convenção de direito internacional privado, de Havana. Disponível em: $<$ http://www2.camara.leg.br/legin/fed/decret/1920-1929/decreto-18871-13-agosto-1929549000-publicacaooriginal-64246-pe.html>. Acesso em: 01/10/2018.

. Decreto-lei $n^{0}$ 5.452, de $1^{\circ}$ de maio de 1943. Aprova a Consolidação das Leis do Trabalho. Disponível em: <http://www.planalto.gov.br/ccivil_03/decretolei/Del5452compilado.htm>. Acesso em: 24/06/2017.

. Decreto $n^{\mathbf{0}}$ 41.721, de 25 de junho de 1957. Promulga as Convenções Internacionais do Trabalho de $n^{\circ} 11,12,13,14,19,26,29,81,88,89,95,99,100$ e 101 , firmadas pelo Brasil e outros países em sessões da Conferência Geral da Organização Internacional do Trabalho. Disponível em: $<$ http://www.planalto.gov.br/ccivil_03/decreto/antigos/d41721.htm>. Acesso em: 25/06/2017.

. Decreto n⿳ 1.254, de 29 de setembro de 1994. Promulga a Convenção número 155 , da Organização Internacional do Trabalho, sobre Segurança e Saúde dos Trabalhadores e o Meio Ambiente de Trabalho, concluída em Genebra, em 22 de junho de 1981. Disponível em: <http://www.planalto.gov.br/ccivil_03/decreto/1990-1994/D1254.htm>. Acesso em: 25/06/2017.

. Decreto $n^{0}$ 3.048, de 6 de maio de 1999. Aprova o Regulamento da Previdência Social, e dá outras providências. Disponível em: $<$ http://www.planalto.gov.br/ccivil_03/decreto/D3048.htm>. Acesso em: 18/10/2018.

. Decreto $n^{0}$ 4.552, de 27 de dezembro de 2002. Aprova o Regulamento da Inspeção do Trabalho. Disponível em: $<$ http://www.planalto.gov.br/ccivil_03/decreto/2002/d4552.htm>. Acesso em: 16/10/2018. 
Decreto $\mathrm{n}^{0}$ 5.063, de 3 de maio de 2004. Aprova a Estrutura Regimental e o Quadro Demonstrativo dos Cargos em Comissão e das Funções Gratificadas do Ministério do Trabalho e Emprego, e dá outras providências. Disponível em: $<$ http://www.planalto.gov.br/ccivil_03/_Ato2004-2006/2004/Decreto/D5063.htm>. Acesso em: 01/04/2018.

Decreto $\mathrm{n}^{0}$ 6.341, de 3 de janeiro de 2008. Dá nova redação a dispositivos do Anexo I e altera o Anexo II, “a”, do Decreto no 5.063, de 3 de maio de 2004, que aprova a Estrutura Regimental e o Quadro Demonstrativo dos Cargos em Comissão e das Funções Gratificadas do Ministério do Trabalho e Emprego. Disponível em: $<$ http://www.planalto.gov.br/ccivil_03/_ato2007-2010/2008/decreto/d6341.htm>. Acesso em: $01 / 04 / 2018$.

Decreto $\mathbf{n}^{0}$ 7.602, de 7 de novembro de 2011. Dispõe sobre a Política Nacional de Segurança e Saúde no Trabalho - PNSST. Disponível em: $<$ http://www.planalto.gov.br/ccivil_03/_ato2011-2014/2011/decreto/D7602.htm>. Acesso em: $14 / 10 / 2018$.

. Decreto $n^{0}$ 8.894, de 3 de novembro de 2016. Aprova a Estrutura Regimental e o Quadro Demonstrativo dos Cargos em Comissão e das Funções de Confiança do Ministério do Trabalho, remaneja cargos em comissão e funções gratificadas e substitui cargos em comissão do Grupo Direção e Assessoramento Superior - DAS por Funções Comissionadas do Poder Executivo - FCPE. Disponível em: $<$ http://www.planalto.gov.br/ccivil_03/_Ato2015-2018/2016/Decreto/D8894.htm\#art11>. Acesso em: 01/04/2018.

INSTITUTO NACIONAL DA SEGURIDADE SOCIAL. Instrução Normativa $\overline{\text { DC/INSS }} \mathbf{n}^{\circ} 98$ de 05/12/2003. Aprova Norma Técnica sobre Lesões por Esforços Repetitivos - LER ou Distúrbios Osteomusculares Relacionados ao Trabalho - DORT. Disponível em: $<$ https://www.legisweb.com.br/legislacao/?id=75579>. Acesso em: 13/10/2018.

Lei complementar $\mathbf{n}^{0} \mathbf{1 5 0}$, de $\mathbf{1}^{\mathbf{0}}$ de junho de 2015. Dispõe sobre o contrato de trabalho doméstico; altera as Leis no 8.212, de 24 de julho de 1991, no 8.213, de 24 de julho de 1991, e no 11.196, de 21 de novembro de 2005; revoga o inciso I do art. 3o da Lei no 8.009, de 29 de março de 1990, o art. 36 da Lei no 8.213, de 24 de julho de 1991, a Lei no 5.859 , de 11 de dezembro de 1972, e o inciso VII do art. 12 da Lei no 9.250, de 26 de dezembro 1995; e dá outras providências. Disponível em: $<$ http://www.planalto.gov.br/ccivil_03/leis/LCP/Lcp150.htm>. Acesso em: 16/10/2018.

Lei $n^{\circ}$ 4.657, de 4 de setembro de 1942. Institui a

Lei de Introdução às normas do Direito Brasileiro. Disponível em: $<$ https://www.planalto.gov.br/CCIVIL_03/Decreto-Lei/Del4657compilado.htm $>$. Acesso em: 30/09/2018.

Lei $\mathbf{n}^{\mathbf{0}}$. 4.886, de 9 de dezembro de 1965. Regula as atividades dos representantes comerciais autônomos. Disponível em: $<$ http://www.planalto.gov.br/ccivil_03/leis/14886.htm>. Acesso em: Acesso em: 24/06/2017. 
. Lei n⿳ 7.064, de 6 de dezembro de 1982. Dispõe sobre a situação de trabalhadores contratados ou transferidos para prestar serviços no exterior. Disponível em: $<$ http://www.planalto.gov.br/ccivil_03/LEIS/L7064.htm>. Acesso em: 05/10/2018.

. Lei $\mathbf{n}^{0}$ 8.213, de 24 de julho de 1991. Dispõe sobre os Planos de Benefícios da Previdência Social e dá outras providências. Disponível em: $<$ http://www.planalto.gov.br/ccivil_03/leis/L8213compilado.htm>. Acesso em: 05/07/2017.

. Lei $\mathrm{n}^{0}$ 10.406, de 10 de janeiro de 2002. Institui o Código Civil. Disponível em: $<$ http://www.planalto.gov.br/ccivil_03/leis/2002/L10406compilada.htm>. Acesso em: 09/07/2017.

. Lei $\mathbf{n}^{\circ}$ 11.962, de 3 de julho de 2009. Altera o art. 1o da Lei no 7.064, de 6 de dezembro de 1982, estendendo as regras desse diploma legal a todas as empresas que venham a contratar ou transferir trabalhadores para prestar serviço no exterior. Disponível em: $\quad$ http://www.planalto.gov.br/ccivil_03/_Ato2007-2010/2009/Lei/L11962.htm>. Acesso em: 05/10/2018.

. Lei $n^{0}$ 12.551, de 15 de dezembro de 2011. Altera o art. 6o da Consolidação das Leis do Trabalho (CLT), aprovada pelo Decreto-Lei no 5.452, de 1o de maio de 1943, para equiparar os efeitos jurídicos da subordinação exercida por meios telemáticos e informatizados à exercida por meios pessoais e diretos. Disponível em: $<$ http://www.planalto.gov.br/ccivil_03/_ato2011-2014/2011/lei/112551.htm>. Acesso em: 08/07/2017.

. Lei $\mathbf{n}^{0}$ 13.257, de 8 de março de 2016.

Dispõe sobre as políticas públicas para a primeira infância e altera a Lei no 8.069, de 13 de julho de 1990 (Estatuto da Criança e do Adolescente), o Decreto-Lei no 3.689, de 3 de outubro de 1941 (Código de Processo Penal), a Consolidação das Leis do Trabalho (CLT), aprovada pelo Decreto-Lei no 5.452, de 1o de maio de 1943, a Lei no 11.770 , de 9 de setembro de 2008, e a Lei no 12.662, de 5 de junho de 2012. Disponível em: $<$ http://www.planalto.gov.br/ccivil_03/_Ato2015-2018/2016/Lei/L13257.htm>. Acesso em: $01 / 10 / 2018$.

. Lei n⿳ 13.467, de 13 de julho de 2017. Altera a Consolidação das Leis do Trabalho (CLT), aprovada pelo Decreto-Lei no 5.452, de 1o de maio de 1943, e as Leis nos 6.019, de 3 de janeiro de 1974, 8.036, de 11 de maio de 1990, e 8.212, de 24 de julho de 1991, a fim de adequar a legislação às novas relações de trabalho. Disponível em: $<$ http://www.planalto.gov.br/ccivil_03/_Ato2015-2018/2017/Lei/L13467.htm\#art1>. Acesso em: 04/02/2018.

. Lei $\mathbf{n}^{0}$ 13.709, de 14 de agosto de 2018. Dispõe sobre a proteção de dados pessoais e altera a Lei $n^{\circ} 12.965$, de 23 de abril de 2014 (Marco Civil da Internet). Disponível em: $<$ http://www.planalto.gov.br/ccivil_03/_Ato2015-2018/2018/Lei/L13709.htm>. Acesso em: $21 / 10 / 2018$.

. Medida Provisória $\mathbf{n}^{\circ}$ 870, de $1^{\circ}$ de janeiro de 2009. Estabelece a organização básica dos órgãos da Presidência da República e dos Ministérios. Disponível em: $<$ http://www.planalto.gov.br/ccivil_03/_Ato2019-2022/2019/Mpv/mpv870.htm>. Acesso em: 05/01/2009. 
. MINISTÉRIO DO TRABALHO E EMPREGO. Portaria n 3.214 , de 08 de junho de 1978. Aprova as Normas Regulamentadoras - NR - do Capítulo V, Título II, da Consolidação das Leis do Trabalho, relativas a Segurança e Medicina do Trabalho. Disponível em: <http://sislex.previdencia.gov.br/paginas/63/MTE/1978/3214.htm>. Acesso em: $12 / 10 / 2018$.

. MINISTÉRIO DO TRABALHO E EMPREGO. Portaria $\mathrm{n}^{\circ} 3.214$, de 08 de junho de 1978. NR 1 - Disposições Gerais. Disponível em: $<$ http://www.trtsp.jus.br/geral/tribunal2/LEGIS/CLT/NRs/NR_1.html $>$. Acesso em: 08/07/2018.

MINISTÉRIO DO TRABALHO E EMPREGO. Portaria $n^{\circ} 3.214$, de 08 de junho de 1978. NR 4 - Serviços especializados em engenharia de segurança e em medicina do trabalho.

Disponível

em: $<$ http://www.trtsp.jus.br/geral/tribunal2/LEGIS/CLT/NRs/NR_4.html>. Acesso em: 28/06/2018.

. MINISTÉRIO DO TRABALHO E EMPREGO. Portaria $\mathrm{n}^{\circ} 3.214$, de 08 de junho de 1978. NR 5 - Comissão Interna de Prevenção de Acidentes. Disponível em: $<$ http://www.trtsp.jus.br/geral/tribunal2/LEGIS/CLT/NRs/NR_5.html $>$. Acesso em: 28/06/2018.

. MINISTÉRIO DO TRABALHO E EMPREGO. Portaria n ${ }^{\circ} 3.214$, de 08 de junho de 1978. NR 7 - Programa de Controle Médico de Saúde Ocupacional. Disponível em: $<$ http://www.trtsp.jus.br/geral/tribunal2/LEGIS/CLT/NRs/NR_7.html>. Acesso em: 28/06/2018.

. MINISTÉRIO DO TRABALHO E EMPREGO. Portaria $\mathrm{n}^{\circ} 3.214$, de 08 de junho de 1978. NR 9 - Programa de Prevenção de Riscos Ambientais. Disponível em: $<$ http://www.trtsp.jus.br/geral/tribunal2/LEGIS/CLT/NRs/NR_9.html $>$. Acesso em: 28/06/2018.

. MINISTÉRIO DO TRABALHO E EMPREGO. Portaria $\mathrm{n}^{\circ} 3.214$, de 08 de junho de 1978. NR 15 - Atividades e operações insalubres. Disponível em: $<$ http://www.trtsp.jus.br/geral/tribunal2/LEGIS/CLT/NRs/NR_15.html>. Acesso em: 28/06/2018.

. MINISTÉRIO DO TRABALHO E EMPREGO. Portaria $n^{\circ} 3.214$, de 08 de junho de 1978. NR 16 - Atividades e operações perigosas. Disponível em: $<$ http://www.trtsp.jus.br/geral/tribunal2/LEGIS/CLT/NRs/NR_16.html>. Acesso em: 28/06/2018.

. MINISTÉRIO DO TRABALHO E EMPREGO. Portaria n ${ }^{\circ} 3.214$, de 08 de junho de 1978. NR 17 - $\quad$ Ergonomia. Disponível em: $<$ http://trabalho.gov.br/images/Documentos/SST/NR/NR17.pdf $>$. Acesso em: 04/03/2018.

. Secretaria de Segurança e Saúde no Trabalho. Portaria SSST no 2 de 10/04/1996. Disponível em: <https://www.legisweb.com.br/legislacao/?id=304076>. Acesso em: $14 / 10 / 2018$. 
. SENADO FEDERAL. Projeto de Lei do Senado $\mathbf{n}^{\circ}$ 274, de 2013. Modifica a Consolidação das Leis do Trabalho (CLT), aprovada pelo Decreto-Lei $n^{\circ} 5.452$, de $1^{\circ}$ de maio de 1943, para dispor sobre a relação de emprego em regime de teletrabalho. Disponível em: <http://www25.senado.leg.br/web/atividade/materias/-/materia/113558>. Acesso em: 08/07/2017.

. SENADO FEDERAL. Projeto de Lei do Senado no 326, de 2013. Acrescenta ao Título IV da Consolidação das Leis do Trabalho (CLT), aprovada pelo Decreto-Lei $n^{\circ} 5.452$, de $1^{\circ}$ de maio de 1943, o Capítulo VIII-A para dispor sobre o trabalho exercido a distância. Disponível em: <http://www25.senado.leg.br/web/atividade/materias/-/materia/113905>. Acesso em: 08/07/2017.

. SENADO FEDERAL. Projeto de Lei da Câmara no 38, de 2017. Disponível em:

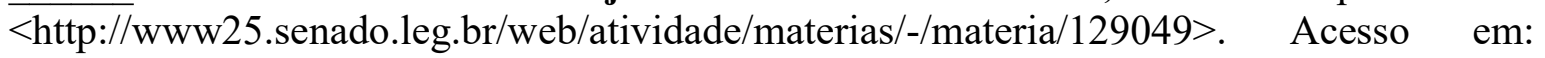
09/07/2017.

SENADO FEDERAL. COMISSÃO DE ASSUNTOS ECONÔMICOS. Parecer relatado pelo Senador Ricardo Ferraço, sobre o Projeto de Lei da Câmara ${ }^{\circ}{ }^{38}$, de 2017, que altera a Consolidação das Leis do Trabalho (CLT), aprovada pelo DecretoLei $n^{0}$ 5.452, de $1^{\circ}$ de maio de 1943, e as Leis $n^{0}$ s 6.019, de 3 de janeiro de 1974, 8.036, de 11 de maio de 1990, e 8.212, de 24 de julho de 1991, a fim de adequar a legislação às novas relações de trabalho. Brasília, 23 maio de 2017. Disponível em: $<$ http://legis.senado.leg.br/sdleg-getter/documento?dm=5302372\&disposition=inline $>$. Acesso em: 06/05/2018.

. SENADO FEDERAL. COMISSÃO DE ASSUNTOS SOCIAIS. Parecer relatado pelo Senador Paulo Paim, sobre o Projeto de Lei da Câmara no 38, de 2017, que altera a Consolidação das Leis do Trabalho (CLT), aprovada pelo Decreto-Lei $n^{\circ}$ 5.452, de $1^{\circ}$ de maio de 1943, e as Leis $n^{\circ}$ s 6.019, de 3 de janeiro de 1974, 8.036, de 11 de maio de 1990, e 8.212, de 24 de julho de 1991, a fim de adequar a legislação às novas relações de trabalho. Brasília, 20 de junho de 2017. Disponível em: $<$ http://legis.senado.leg.br/sdleggetter/documento?dm=5349695\&disposition=inline $>$. Acesso em: 28/06/2018.

. SENADO FEDERAL. COMISSÃO DE CONSTITUIÇÃO E JUSTIÇA E DE $\overline{C I D A D} A N I A$. Parecer relatado pelo Senador Romero Jucá, sobre o Projeto de Lei da Câmara no 38, de 2017, que altera a Consolidação das Leis do Trabalho (CLT), aprovada pelo Decreto-Lei $n^{0} 5.452$, de $1^{\circ}$ de maio de 1943, e as Leis $n^{\circ}$ s 6.019, de 3 de janeiro de 1974, 8.036, de 11 de maio de 1990, e 8.212, de 24 de julho de 1991, a fim de adequar a legislação às novas relações de trabalho. Brasília, 28 de junho de 2017. Disponível em: $\quad<$ http://legis.senado.leg.br/sdleggetter/documento?dm=5375790\&disposition=inline $>$. Acesso em: 28/06/2018.

. SENADO FEDERAL. COMISSÃO DE ASSUNTOS ECONÔMICOS. Emenda $\overline{n^{0}} 147$ ao Projeto de Lei da Câmara no 38, de 2017, proposta pelo Senador Lindbergh Farias. Disponível em: $\quad<$ http://legis.senado.leg.br/sdleggetter/documento?dm=5299618\&disposition=inline\#Emenda147 $>. \quad$ Acesso em: 28/06/2018. 
Sindicato Nacional dos Auditores Fiscais do Trabalho. Precedentes administrativos. Disponível em: $<$ https://www.sinait.org.br/site/precedentes $>$. Acesso em: $14 / 10 / 2018$.

Súmulas, Orientações Jurisprudenciais (Tribunal Pleno/Órgão Especial, SBDI-I, SBDI-I Transitória, SBDI-II e SDC), Precedentes Normativos. Brasília: Tribunal Superior do Trabalho, 2016. Disponível em: $<$ http://tst.jus.br/documents/10157/63003/Livro-Internet.pdf $>$. Acesso em: 08/07/2016.

. TRIBUNAL DE JUSTIÇA DO ESTADO DE SÃO PAULO. Provimento Conjunto $\mathrm{n}^{0}$ 5/2015, da Presidência do Tribunal de Justiça e da Corregedoria Geral da Justiça. Dispõe sobre a regulamentação do teletrabalho (home office) no âmbito do Tribunal de Justiça do Estado de São Paulo. Disponível em: <http://biblioteca.mpsp.mp.br/PHL_IMG/TJSP/005provconj\%202015.pdf >. Acesso em: 28/06/2018.

. TRIBUNAL REGIONAL DO TRABALHO DA 2 $2^{\mathrm{a}}$ REGIÃO. Dissídio coletivo de $\overline{\text { greve }}^{\circ}$ 20045001620115020000. Suscitante: SINDICATO DOS EMPREGADOS EM EMPRESAS DE PROCESSAMENTO DE DADOS E EMPREGADOS EM EMPRESAS DE PROCESSAMENTO DE DADOS NO ESTADO DE SÃO PAULO - SINDPD/SP. Suscitado: SINDICATO DAS EMPRESAS DE PROCESSAMENTO DE DADOS E SERVIÇOS DE INFORMÁTICA NO ESTADO DE SÃO PAULO - SEPROSP. Relatora Desembargadora: Maria Isabel Cueva Moraes. Data de Julgamento: 25/05/2011. Órgão julgador: Seção Especializada em Dissídios Coletivos. Disponível em: $<\mathrm{http}$ :/www.sindpd.org.br/sindpd/upload/convencoes/acordao_greve2011.pdf $>$. Acesso em: 27/05/2018.

. TRIBUNAL REGIONAL FEDERAL DA 4 ${ }^{\mathrm{a}}$ REGIÃO. Resolução n ${ }^{\circ}$ 92, de 28 de maio de 2013. Regulamenta o teletrabalho no âmbito da Justiça Federal de $1^{\circ}$ e $2^{\circ}$ Graus da $4^{\mathrm{a}}$ Região e dá outras providências. Disponível em: $<$ https://www2.trf4.jus.br/trf4/upload/editor/svr_resolucao-92-2013---teletrabalho.pdf $>$. Acesso em: 04/03/2018.

. TRIBUNAL REGIONAL FEDERAL DA $4^{\mathrm{a}}$ REGIÃO. Resolução $\mathrm{n}^{\circ}$ 53, de 09 de junho de 2015. Regulamenta o teletrabalho no âmbito da Justiça Federal de $1^{\circ}$ e $2^{\circ}$ Graus da $4^{\mathrm{a}}$ Região e dá outras providências. Disponível em: $<$ https://www2.trf4.jus.br/trf4/diario/visualiza_documento_adm.php?orgao=1\&id_materia $=25684 \&$ reload $=$ false $>$. Acesso em: 01/04/2018.

. TRIBUNAL SUPERIOR DO TRABALHO. Resolução Administrativa no $\mathbf{n}^{0}$ 1.499,

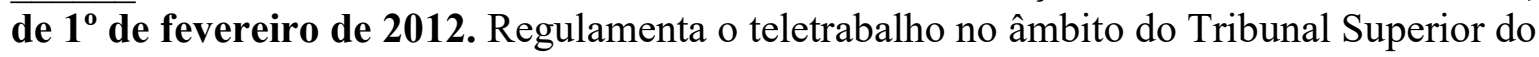
Trabalho e dá outras providências. Disponível em: $<$ https://juslaboris.tst.jus.br/bitstream/handle/1939/19477/2012_ra1499_compilado.pdf?seq uence $=2 \&$ isAllowed $=\mathrm{y}>$. Acesso em: 04/03/2018.

. TRIBUNAL SUPERIOR DO TRABALHO. Ato $\mathbf{n}^{\mathbf{0}}$ 47/SEGPES.GDGSET.GP, de 15 de fevereiro de 2018. Regulamenta o teletrabalho no âmbito do Tribunal Superior do Trabalho e dá outras providências. Disponível em: $<$ https://juslaboris.tst.jus.br/bitstream/handle/1939/124970/2018_ato0047.pdf?sequence=1 \&isAllowed=y>. Acesso em: 04/03/2018. 
COLÔMBIA. Ley 1221 de 2008 Nivel Nacional (Julio 16). Ley por la cual se establecen normas para promover y regular el Teletrabajo y se dictan otras disposiciones. Disponível em: <http://www.bogotajuridica.gov.co/sisjur/normas/Norma1.jsp?i=31431>. Acesso em: 27/05/2018.

. Decreto 884 de 2012 Nivel Nacional (Abril 30). Decreto por medio del cual se reglamenta la Ley 1221 de 2008 y se dictan otras disposiciones. Disponível em: $<$ http://www.bogotajuridica.gov.co/sisjur/normas/Norma1.jsp?i=31431>. Acesso em: $27 / 05 / 2018$.

. Decreto Único Reglamentario 1072 de 2015 Nivel Nacional (Mayo 26). Decreto por medio del cual se expide el Decreto Único Reglamentario del Sector Trabajo. Disponível em: $\quad<$ http://www.bogotajuridica.gov.co/sisjur/normas/Norma1.jsp?i=62506\#2.2.1.5.1 $>$. Acesso em: 28/06/2018.

Comissão Interamericana de Direitos Humanos. Protocolo Adicional à Convenção Americana sobre Direitos Humanos em matéria de direitos econômicos, sociais e Culturais, "Protocolo de San Salvador". Disponível em: $<$ http://www.cidh.org/Basicos/Portugues/e.Protocolo_de_San_Salvador.htm $>$. Acesso em: $16 / 10 / 2018$.

CONFEDERACIÓN EUROPEA DE SINDICATOS; et al. Acuerdo Marco Europeo sobre Teletrabajo. [S.I.]: CCOO, jul. 2011. Disponível em: <https://www.ccooservicios.es/archivos/bbva/20110727_acuerdo_marco_europeo_teletrabajo.pdf $>$. Acesso em: 30/06/2018.

CONSELHO EUROPEU. Directiva 93/104/CE, de 23 de Novembro de 1993. Relativa a determinados aspectos da organização do tempo de trabalho. Disponível em: $<$ https://eurlex.europa.eu/legal-content/PT/TXT/?uri=CELEX\%3A31993L0104>. Acesso em $19 / 10 / 2018$

. Directiva 2003/88/CE, de 4 de novembro de 2003. Relativa a determinados aspectos da organização do tempo de trabalho. Disponível em: <https:/eurlex.europa.eu/legal-content/PT/TXT/?uri=CELEX:32003L0088>. Acesso em 19/08/2018.

. Directiva 89/391/CEE, de 12 de junho de 1989. Relativa à aplicação de medidas destinadas a promover a melhoria da segurança e da saúde dos trabalhadores no trabalho. Disponível em: $\quad<$ http://eur-lex.europa.eu/legalcontent/PT/TXT/PDF/?uri=CELEX:01989L0391-20081211\&from=EN>. Acesso em 25/06/2017.

CORNELL LAW SCHOOL. Amendment IV. Disponível em: $<$ https://www.law.cornell.edu/constitution/fourth_amendment $>$. Acesso em: 18/02/2018.

COSTA RICA. Decreto del Poder Ejecutivo $n^{\mathbf{0}}$ 37695-MP-MTSS. Promocion del teletrabajo en las instituciones públicas. Disponível em: $<$ http://www.ilo.org/dyn/natlex/docs/ELECTRONIC/94875/111506/F313548990/CRI9487 5.pdf $>$. Acesso em: 29/06/2018. 
ESPANHA. Ley 31/1995, de 8 de noviembre 1995. Ley de prevención de Riesgos Laborales. Disponível em: <https://www.boe.es/diario_boe/txt.php?id=BOE-A-199524292>. Acesso em: 03/07/2017.

Real Decreto Legislativo 1/1995, de 24 de marzo 1995. Aprueba el texto refundido de la Ley del Estatuto de los Trabajadores. Disponível em: $<$ https://www.boe.es/buscar/doc.php?id=BOE-A-1995-7730>. Acesso em: 03/07/2017.

. Real Decreto 488/1997, de 14 de abril 1997. Establece disposiciones mínimas de seguridad y salud relativas al trabajo con equipos que incluyen pantallas de visualización. Disponível em: <https://www.boe.es/buscar/doc.php?id=BOE-A-1997-8671>. Acesso em: 03/07/2017.

Real Decreto Legislativo 2/2015, de 23 de octubre 2015. Aprueba el texto refundido de la Ley del Estatuto de los Trabajadores. Disponível em: $<$ https://www.boe.es/buscar/act.php?id=BOE-A-2015-11430>. Acesso em: 03/07/2017.

ESTADOS UNIDOS DA AMÉRICA. Telework Enhancement Act. (2010) Disponível em: $<$ https://www.gpo.gov/fdsys/pkg/BILLS-111hr1722enr/pdf/BILLS-111hr1722enr.pdf $>$. Acesso em: 20/10/2018.

EUR-Lex. Convenção de Roma de 1980 sobre a lei aplicável às obrigações contratuais (versão consolidada). Jornal Oficial no C 027 de 26/01/1998 p. 0034 - 0046. Disponível em:

$<$ https://eur-lex.europa.eu/legalcontent/PT/TXT/?uri=CELEX\%3A41998A0126\%2802\%29>. Acesso em: 04/10/2018.

FRANÇA. Code du travail. Version consolidée au 10 octobre 2018. Disponível em: $<$ https://www.legifrance.gouv.fr/affichCode.do?cidTexte=LEGITEXT000006072050 $>$. Acesso em: 17/10/2018.

HUNGRIA. Act I of 2012 on the Labor Code. Disponível em: $<$ https://www.ilo.org/dyn/natlex/docs/ELECTRONIC/89886/103370/F373393512/Act.I.of. 2012.on.the.Labor.Code.2018.pdf>. Acesso em: 21/10/2018.

INTERNATIONAL LABOUR ORGANIZATION (ILO). Constituição da OIT e Declaração de Filadélfia. Disponível em: <https://www.ilo.org/brasilia/conheca-aoit/WCMS_336957/lang--pt/index.htm>. Acesso em: 04/10/2018.

Disponível

C001 - Hours of Work (Industry) Convention. Washington: ILO, 1919. $<$ https://www.ilo.org/dyn/normlex/en/f?p=NORMLEXPUB:12100:::NO:12100:P12100_I

LO_CODE:C001:NO>. Acesso em: 08/10/2018.

Disponível

C129 - Labour Inspection (Agriculture) Convention. Geneva: ILO, 1969.

$<$ http://www.ilo.org/dyn/normlex/en/f?p=NORMLEXPUB:12100:::NO:12100:P12100 IL

O_CODE:C129:NO>. Acesso em: 25/06/2017. 
C177 - Home Work Convention. Geneva: ILO, 1996. Disponível em:

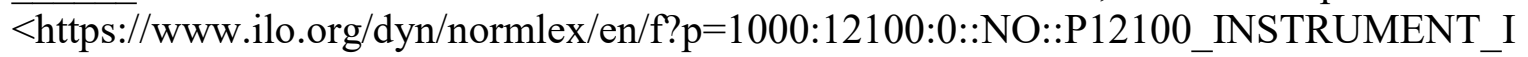
D,P12100_LANG_CODE:312322,es:NO>. Acesso em: 10/10/2018.

. C187 - Promotional Framework for Occupational Safety and Health Convention. Geneva: ILO, 2006. Disponível em: $<$ https://www.ilo.org/dyn/normlex/en/f?p=1000:12100:0::NO::P12100_INSTRUMENT_I D,P12100_LANG_CODE:312332,es:NO>. Acesso em: 10/10/2018.

Disponível

R164 - Occupational Safety and Health Recommendation. Geneva: ILO, 1981. $<$ https://www.ilo.org/dyn/normlex/en/f?p=1000:12100:0::NO::P12100_INSTRUMENT_I D,P12100_LANG_CODE:312502,es:NO>. Acesso em: 10/10/2018.

R184 - Home Work Recommendation. Geneva: ILO, 1996. Disponível em: $\overline{<\mathrm{https}}$ //www.ilo.org/dyn/normlex/en/f?p=1000:12100:0::NO::P12100_INSTRUMENT_I D,P12100_LANG_CODE:312522,es:NO>. Acesso em: 10/10/2018.

ITÁLIA. Legge 16 giugno 1998, n. 191. "Modifiche ed integrazioni alle leggi 15 marzo 1997, n. 59, e 15 maggio 1997, n. 127, nonche' norme in materia di formazione del personale dipendente e di lavoro a distanza nelle pubbliche amministrazioni. Disposizioni in materia di edilizia scolastica." Disponível em: $<$ http://www.parlamento.it/parlam/leggi/981911.htm>. Acesso em: 29/06/2018.

OFICINA INTERNACIONAL DEL TRABAJO; MINISTERIO DE TRABAJO, EMPLEO Y SEGURIDAD SOCIAL; UNIÓN INDUSTRIAL ARGENTINA. Manual de buenas prácticas en teletrabajo. $1^{\text {ra }}$ ed. Buenos Aires, 2011. Disponível em: $<$ http://www.ilo.org/wcmsp5/groups/public/---americas/---ro-lima/---ilobuenos_aires/documents/publication/wcms_bai_pub_143.pdf $>$. Acesso em: 08/04/2018.

ORGANIZATION OF AMERICAN STATES. Convenção Interamericana sobre Direito Aplicável Aos Contratos Internacionais. Disponível em: $<\mathrm{http}$ :/www.oas.org/juridico/portuguese/treaties/b-56.htm>. Acesso em: 06/10/2018.

PERU. Ley $\mathbf{n}^{0}$ 30036. Ley que regula el teletrabajo. (04/06/2013) Disponível em: $<$ http://www2.congreso.gob.pe/sicr/cendocbib/con4_uibd.nsf/DD7DF93E4B76742105257 EF4000325BA/\$FILE/30036.pdf>. Acesso em: 20/10/2018.

. Decreto Supremo no 017-2015-TR. Decreto Supremo que aprueba el Reglamento $\overline{\mathrm{de}}$ la Ley $\mathrm{N}^{\circ}$ 30036, Ley que regula el Teletrabajo. Disponível em: $<$ http://www.aprodeh.org.pe/documentos/marconormativo/discapacidad/Decreto_Supremo_017-2015-

TR_aprueba_Reglamento_Ley_de_Teletrabajo.pdf >. Acesso em: 20/10/2018.

PORTUGAL. Lei no 99/2003, de 27 de Agosto de 2003. Aprova o Código do Trabalho. Disponível em: <http://cite.gov.pt/Legis_Nac/ArquivoLN/LeisArqLN/Lei99_03.htm>. Acesso em: 30/06/2018.

Lei $\mathbf{n}^{\circ}$ 35/2004, de 29 de julho de 2004. Regulamenta a Lei n. ${ }^{\circ}$ 99/2003, de 27 de Agosto, que aprovou o Código do Trabalho. Disponível em: 
$<$ http://cite.gov.pt/Legis_Nac/ArquivoLN/LeisArqLN/Lei35_04_01.htm\#c03>. Acesso em: 30/06/2018.

Trabalho.

Lei $n^{0}$ 7/2009, de 12 de fevereiro de 2009. Aprova a revisão do Código do

$<$ http//cite gov pt/asstscite/downloads/legislacao/CT25082016.pdf $>$ Acesso em:

03/07/2017.

ROMÊNIA. Legea nr. $81 / 2018$ privind reglementarea activității de telemuncă. (Providencia a regulamentação do teletrabalho) Disponível em: $<$ https://lege5.ro/Gratuit/gi3tknrrgm2a/legea-nr-81-2018-privind-reglementarea-activitatiide-telemunca $>$. Acesso em: 20/10/2018.

SEPROSP - SINDICATO DAS EMPRESAS DE PROCESSAMENTO DE DADOS E SERVIÇOS DE INFORMÁTICA DO ESTADO DE SÃO PAULO; SINDPD SINDICATO DOS TRABALHADORES EM PROCESSAMENTO DE DADOS E EMPREGADOS DE EMPRESAS DE PROCESSAMENOT DE DADOS DO ESTADO DE SÃO PAULO. Convenção coletiva de trabalho para o ano 2002. Disponível em: $<$ http://www.sindpd.org.br/sindpd/upload/convencoes/cct_2002.pdf $>$. Acesso em: $27 / 05 / 2018$.

. Convenção coletiva de trabalho para o ano 2003. Disponível em:

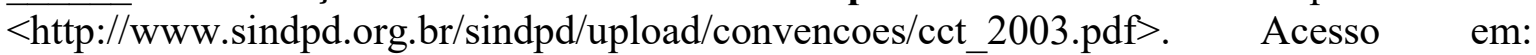
$27 / 05 / 2018$.

Convenção coletiva de trabalho para o ano 2004. Disponível em: $<$ http://www.sindpd.org.br/sindpd/upload/convencoes/cct_2004.PDF>. Acesso em: $27 / 05 / 2018$.

Convenção coletiva de trabalho para o ano 2005. Disponível em:

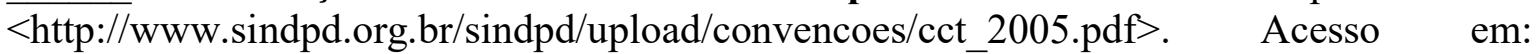
$27 / 05 / 2018$.

. Convenção coletiva de trabalho para o ano 2006. Disponível em:

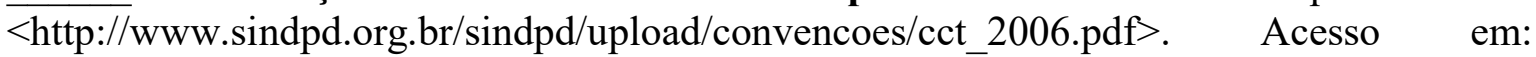
27/05/2018.

Convenção coletiva de trabalho para o ano 2007. Disponível em:

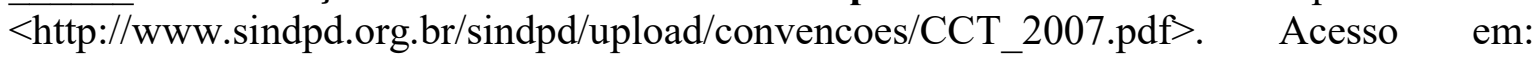
27/05/2018.

- Convenção coletiva de trabalho para o ano 2008. Disponível em:

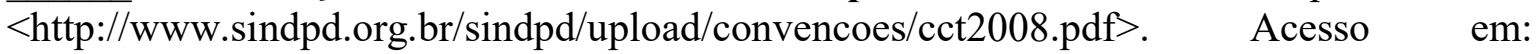
$27 / 05 / 2018$.

Convenção coletiva de trabalho para o ano 2009. Disponível em:

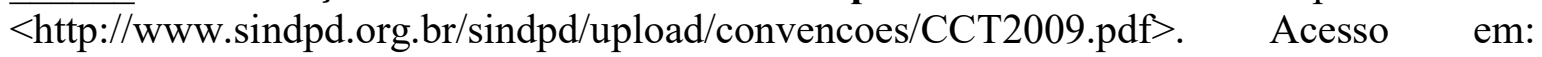
27/05/2018. 
- Convenção coletiva de trabalho para o ano 2010. Disponível em: $<$ http://www.sindpd.org.br/sindpd/upload/convencoes/cct2010.pdf $>$. Acesso em: $27 / 05 / 2018$.

. Convenção coletiva de trabalho para o ano 2012. Disponível em: $\overline{<\mathrm{http} / / /}$ www.sindpd.org.br/sindpd/upload/convencoes/cct2012.pdf $>$. Acesso em: $27 / 05 / 2018$.

. Convenção coletiva de trabalho para o ano 2013. Disponível em: $<\mathrm{http}: / /$ www.sindpd.org.br/sindpd/upload/convencoes/cct\%202013\%20homologada.pdf $>$. Acesso em: 27/05/2018.

. Norma coletiva de trabalho 2014. Disponível em:

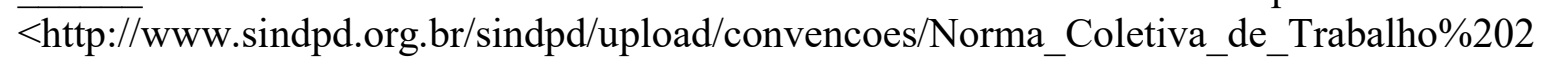
014.pdf $>$. Acesso em: 27/05/2018.

Convenção coletiva de trabalho para o ano 2015. Disponível em:

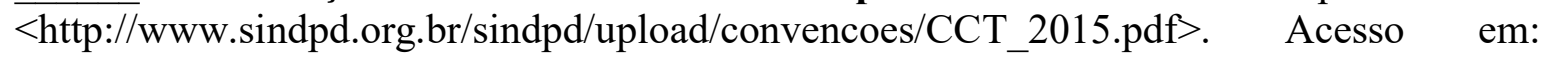
$27 / 05 / 2018$.

. Convenção coletiva de trabalho para o ano 2016. Disponível em: $<\mathrm{http}$ ://www.sindpd.org.br/sindpd/upload/convencoes/CCT2016_.pdf $>$. Acesso em: $27 / 05 / 2018$.

. Convenção coletiva de trabalho para o ano 2017. Disponível em: $\overline{<\mathrm{http}: / / w w w . s i n d p d . o r g . b r / s i n d p d / u p l o a d / c o n v e n c o e s / C C T-2017-h o m o l o g a d a . p d f>. ~}$ Acesso em: 27/05/2018.

UNITED STATES DEPARTMENT OF LABOR. Osha Instruction CPL 2-0.125. Subject: Home-Based Worksites. Effective date: February 25, 2000. Disponível em: $<$ https://www.osha.gov/pls/oshaweb/owadisp.show_document?p_table=DIRECTIVES\&p_ $\mathrm{id}=2254>$. Acesso em: 18/02/2018.

VATICANO. Carta encíclica "Rerum Novarum" sobre a condição dos operários, do sumo pontífice Papa Leão XIII, a todos os nossos veneráveis irmãos, os patriarcas, primazes, arcebispos e bispos do orbe católico, em graça e comunhão com a sé apostólica. Libreria Editrice Vaticana. Dada em Roma, junto de S. Pedro, a 15 de maio de 1891. Disponível em: $<$ http://w2.vatican.va/content/leo-xiii/pt/encyclicals/documents/hf_1xiii_enc_15051891_rerum-novarum.html $>$. Acesso em: 06/10/2018.

WORLD HEALTH ORGANIZATION. Constitution of the World Health Organization. Disponível em: $<$ http://www.who.int/governance/eb/who_constitution_en.pdf $>$. Acesso em: 08/10/2018. 


\section{REFERÊNCIAS SECUNDÁRIAS}

AGÊNCIA BRASIL. Os motivos da greve geral desta sexta (28/04) EXAME Brasil, 28 abr. 2017. Disponível em: <https://exame.abril.com.br/brasil/greve-geral-os-motivos-dosprotestos-em-todo-o-pais/>. Acesso em: 30/09/2018.

ALMEIDA, Almiro Eduardo de; SEVERO, Valdete Souto. Direito à desconexão nas relações sociais de trabalho. $2^{\mathrm{a}}$ ed. São Paulo: LTr, 2016.

ALONSO OLEA, Manuel. Introdução ao direito do trabalho. Trad. Carlos Alberto Barata Silva. $4^{\mathrm{a}}$ ed. rev. São Paulo: LTr, 1984.

ALVARENGA, Rúbia Zanotelli de. O teletrabalho e a subordinação estrutural. Revista eletrônica [do] Tribunal Regional do Trabalho da $9^{\text {a }}$ Região, Curitiba, PR, v. 3, n. 33, p. 71-84, set. 2014.

ALVES, Rubens Valtecides. Teletrabalho um conceito complexo no direito brasileiro. Revista da Faculdade de Direito da Universidade Federal de Uberlândia. Uberlândia, v. 35, p. 385-394, jan./dez. 2007.

AMADO, João Leal. Contrato de trabalho. 3ª Edição. Coimbra: Coimbra Editora, 2011.

ANAMATRA (Associação Nacional dos Magistrados da Justiça do Trabalho). Nota Técnica - nove meses de vigência da reforma trabalhista. 2018. Disponível em: $<$ https://www.anamatra.org.br/images/DOCUMENTOS/20180926.notatecnicaOIT.pdf $>$.

Acesso em: 16/10/2018.

ARCOVERDE, Letícia. Pressão para responder rápido mensagem de trabalho pode causar burnout. Valor Econômico, 28 nov. 2014. Disponível em: $<$ https://www.valor.com.br/carreira/3797130/pressao-para-responder-rapido-mensagemde-trabalho-pode-causar-burnout>. Acesso em: 17/10/2018.

ARGENTINA. Superintendencia de Riesgos del Trabajo. Función de las ART. Disponível em: <https://www.srt.gob.ar/index.php/funcion-de-las-art/>. Acesso em: 08/04/2018.

ASTAÍZA, Fernando; et al. Teletrabajo: aspectos sociojurídicos en el campo publicitario. Bogotá: Ediciones Universidad Central, 2017.

BAE, Ilhan. Public Acceptance of Fundamental Rights via a Telepresence Robot and a Video Call Stand in South Korea. International Journal of Social Robotics (2018) 10, p. 503$517 . \quad$ Disponível em: <https://link-springercom.ez67.periodicos.capes.gov.br/content/pdf/10.1007\%2Fs12369-017-0453-4.pdf $>$. Acesso em: 20/10/2018.

BANKÓ, Zoltán; SZÖKE, Gergely László. Issues of Digital Workplace - The Situation in Hungary . JurInfo, Pécs, 2016. Disponível no SSRN: $<$ https://ssrn.com/abstract=2927498>. Acesso em: 21/10/2018. 
BARROS, Alice Monteiro de. Curso de direito do trabalho. $10^{\text {a }}$ ed. atual. por Jessé Claudio Franco de Alencar. São Paulo: LTr, 2016.

BARROSO, Fábio Túlio. O teletrabalho e a subordinação virtual após a Lei n ${ }^{\circ}$ 12.551/2011: novos elementos caracterizadores do Direito Extraordinário do Trabalho. Revista Fórum Trabalhista, ano 1, n. 2, p. 83-100, 2012.

BASTOS, Guilherme Augusto Caputo. TELETRABALHO (telework ou telecommuting): uma nova forma de ver o tempo e o espaço nas relações de trabalho. Sociedade Brasileira de Teletrabalho e Teleatividades. Disponível em: $<$ http://www.sobratt.org.br/site2015/wp-content/uploads/2015/03/TELETRABALHOALTERADO-PROJETO-DE-LEI.docx>. Acesso em: 08/07/2017.

BATALHA, Elton Duarte. Teletrabalho - A reforma trabalhista brasileira e a experiência estrangeira. In: MANNRICH, Nelson (coord.). Reforma trabalhista: reflexões e críticas. São Paulo: LTr, 2018, p. 92-98.

BECCARIA, Cesare Bonesana. Dos delitos e das penas. Trad. Lucia Guidicini e Alessandro Berti Contessa. São Paulo: Martins Fontes, 1997.

BELMONTE, Alexandre Agra. Problemas jurídicos do teletrabalho. Revista de Direito do Trabalho. São Paulo, a. 33, n. 127, p. 13-27, jul./set. 2007.

BELTRAN, Ari Possidonio. Contrato de trabalho transnacional. In: ZAINAGHI, Domingos Sávio; FREDIANI, Yone. Novos rumos de direito do trabalho na América Latina. São Paulo: LTr, 2003, p. 29-45.

BENVINGUT, Ramon Sellas i. El régimen jurídico del teletrabajo en España. Elcano (Navarra): Editorial Aranzadi, 2001.

BOTELHO, Paulo Regis Machado. Contratos de trabalho especiais: teletrabalho e intermitente. In: AGUIAR, Antonio Carlos (coord.). Reforma trabalhista: aspectos jurídicos relevantes. São Paulo: Quartier Latin, 2017, p. 259-272.

BOUCINHAS FILHO, Jorge Cavalcanti. Teletrabalho: interpretação da Lei ${ }^{0} 12.551$ de forma a impedir a superexploração do trabalhador. Jornal Trabalhista Consulex. Brasília, a. 29, n. $1458, \quad$ p. 3-10, 24 dez. 2012. Disponível em: $<$ http://www.lex.com.br/doutrina_24074593_TELETRABALHO_INTEPRETACAO_DA _LEI_12551_DE_FORMA_A_IMPEDIR_A_SUPEREXPLORACAO_DO_TRABAL̄HA DOR.aspx>. Acesso em: 08/07/2017.

BRAMANTE, Ivani Contini. Teletrabalho - teledireção, telessubordinação e teledisposição. Revista LTr. São Paulo, a. 76, t. I, n. 4, p. 391-412, abr. 2012.

BRASIL. CÂMARA DOS DEPUTADOS. PL 6787/16 - REFORMA TRABALHISTA Audiência Pública - 15/03/2017 - 14:56. Disponível em: $<$ https://www.youtube.com/watch?v=DB_pMjD8Hio > . Acesso em: 23/12/2017. 
BRIGNONI, Hugo Fernandez. Las empresas de aplicaciones tecnológicas y el fenómeno Uber. La llamada Economía disruptiva. Derecho Laboral, T. LIX, n. 261, enero-marzo 2016, p. 33-50.

BRITO FILHO, José Claudio Monteiro de; FERREIRA, Vanessa Rocha. A regulamentação do teletrabalho no ordenamento jurídico brasileiro e a reforma trabalhista. In: A reforma trabalhista na visão da Academia Brasileira de Direito do Trabalho. Porto Alegre: LexMagister, 2018, p. 176-185.

BULLAIN, Nilda. TOFTISOVA, Radost. A Comparative Analysis of European Policies and Practices of NGO-Government Cooperation. International Journal of Not-for-Profit Law. Vol. 7, $\mathrm{n}^{\circ}$ 4, September 2005, p. 64-112. Disponível em: <https://heinonline.org>. Acesso em: 07/07/2018.

BUNTING, William. Unlocking the Housing-Related Benefits of Telework: A Case for Government Intervention (August 2, 2017). Real Estate Law Journal, Vol. 46, No. 3, Winter 2017. Disponível no SSRN: <https://ssrn.com/abstract=2994779>. Acesso em: 21/10/2018.

CALVET, Otavio. Direito ao lazer. Rio de Janeiro: Labor, 2010.

CARLINI, Angélica. Seguro de responsabilidade civil com cobertura para empregador e trabalho home office. In: COLNAGO, Lorena de Mello Rezende; CHAVES JUNIOR, José Eduardo de Resende; ESTRADA, Manuel Martín Pino (coords.). Teletrabalho. São Paulo: LTr, 2017, p. 119-124.

CASSAR, Vólia Bomfim. Direito do trabalho. $14^{\mathrm{a}}$ ed. rev., atual., e ampl. São Paulo: Método, 2017.

; BORGES, Leonardo Dias. Comentários à reforma trabalhista. São Paulo: Método, 2017.

CASTELLS, Manuel. A sociedade em rede. Trad. Roneide Venancio Majer. 19a ed. ver. e ampl. São Paulo: Paz e Terra, 2018.

CAVALCANTE, Jouberto de Quadros Pessoa; JORGE NETO, Francisco Ferreira. Notas sobre o sistema jur' diico vigente e a necessidade de uma reflexão sobre a proteção do meio ambiente de trabalho. In: FELICIANO, Guilherme Guimarães; et al (coords.). Direito ambiental do trabalho: apontamentos para uma teoria geral, v. 2, São Paulo: LTr, 2015, p. 293-301.

; JORGE NETO, Francisco Ferreira. Teletrabalho: aspectos econômicos e jurídicos. In: COLNAGO, Lorena de Mello Rezende; CHAVES JUNIOR, José Eduardo de Resende; ESTRADA, Manuel Martín Pino (coords.). Teletrabalho. São Paulo: LTr, 2017, p. 33-38.

. Sociedade, tecnologia e a luta pelo emprego. São Paulo: LTr, 2018.

CEZARIO, Priscila Freire da Silva. Questões polêmicas envolvendo a reforma da regulamentação da jornada de trabalho e das férias. In: MANNRICH, Nelson (coord.).

Reforma trabalhista: reflexões e críticas. São Paulo: LTr, 2018, p. 146-153. 
COASE, Ronald. The Nature of the Firm. Economica. Vol. 14, issue 16, Nov. 1937, p. 386405.

. O problema do custo social. Trad. Francisco Kümmel F. Alves e Renato Vieira Caovilla. The Latin American and Caribbean Journal of Legal Studies. Vol. 3, issue 1, 2008, Article 9, 36 p. Publicado pela primeira vez em 1960, na Journal of Law and Economics 3:1-44.

COLUMBU, Francesca; MASSONI, Túlio de Oliveira. Tempo de trabalho e teletrabalho. In: COLNAGO, Lorena de Mello Rezende; CHAVES JUNIOR, José Eduardo de Resende; ESTRADA, Manuel Martín Pino (coords.). Teletrabalho. São Paulo: LTr, 2017, p. 21-31.

COSTA, Isabel de Sá Affonso da. Controle em novas formas de trabalho: teletrabalhadores e o discurso do empreendimento de si. Cad. EBAPE.BR, Rio de Janeiro, v. 3, n. 1, p. 0112, Mar. $2005 . \quad$ Disponível em: $<$ http://www.scielo.br/scielo.php?script=sci_arttext\&pid=S1679-

$39512005000100009 \& \operatorname{lng}=\mathrm{en} \& n r m=$ iso $>$. Acesso em: 21/10/2018.

COSTA, Ricardo da. A Igreja Católica e a escravidão. Gazeta do Povo, 02 fev. 2013. Disponível em: <https://www.ricardocosta.com/artigo/igreja-catolica-e-escravidao $>$. Acesso em: 30/12/2018.

DE GIORGI, Raffaele. Risks in risk society and the limits of law. A Barriguda: Revista Científica, Campina Grande - PB, v. 2, n. 2, 2012, p. 162-179.

. Ciência do Direito e Legitimação: crítica da epistemologia jurídica alemã de

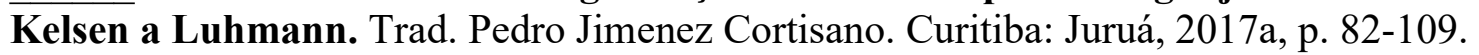

. O futuro do trabalho e o seu Direito. Trad. Luciano Nascimento Silva e Davi Pessoa.

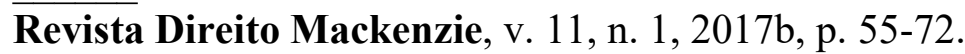

DE MASI, Domenico. O futuro do trabalho: fadiga e ócio na sociedade pós industrial. Tradução de Yadyr A. Figueiredo. 10ª ed. Rio de Janeiro: José Olympio, 2010.

DEGRYSE, Christophe. Digitalisation of the economy and its impact on labour markets. European Trade Union Institute (ETUI), 2016. Disponível em: $<$ https://www.researchgate.net/publication/297392058_Digitalisation_of_the_Economy_an d_its_Impact_on_Labour_Markets>. Acesso em: 09/07/2017.

DELGADO, Mauricio Godinho. Curso de direito do trabalho. $17^{\mathrm{a}}$ ed. rev., atual. e ampl. São Paulo: LTr, 2018.

DESIDÉRIO, Mariana. Por que a Coca-Cola colocou Temer na parede. EXAME Negócios, 21 ago. 2018. Disponível em: < https://exame.abril.com.br/negocios/por-que-acoca-cola-colocou-temer-na-parede-e-ameaca-sair-do-brasil/>. Acesso em: 08/09/2018.

DI MARTINO, Vittorio; WIRTH, Linda. Telework: an overview. Conditions of work digest, Geneve, v.9, n.1., p.1-35, 1990. 
DIAS, Carlos Eduardo Oliveira; et al. Comentários à lei da reforma trabalhista: dogmática, visão crítica e interpretação constitucional. São Paulo: LTr, 2018.

DUQUE, Alba Patricia Guzmán; VILLAMIZAR, Carlos Alberto Abreo. Las habilidades del teletrabajador para la competitividad. Fórum Empresarial, vol. 22, n. 2, Invierno 2017, p. 5-30.

Disponível

em:

$<$ https://revistas.upr.edu/index.php/forumempresarial/article/view/13624/11271>. Acesso em: 20/10/2018.

DUTROW, Kelli L. Working at home at your own risk: employer liability for teleworkers under the occupational safety and health act of 1970. Georgia State University Law Review. Vol. 18, Issue 5 (Summer 2002), p. 955-996. Disponível em: HeinOnline. Acesso em: 18/02/2018.

E-CIDADANIA. Consulta Pública. PlC 38/2017. PROJETO DE LEI DA CÂMARA n ${ }^{\circ}$ 38 de 2017.2 Disponível em: $<$ https://www12.senado.leg.br/ecidadania/visualizacaomateria?id=129049>. Acesso em: 26/12/2017.

E-DEMOCRACIA. Reforma Trabalhista. PL 6787/2016. Disponível em: $<$ https://edemocracia.camara.leg.br/wikilegis/bill/64>. Acesso em: 26/12/2017.

EFE. Japão reconhece 2 novos suicídios por excesso de trabalho no país. Agência EFE, Mundo, 27 set. 2018. Disponível em: <https:/www.efe.com/efe/brasil/mundo/jap-oreconhece-2-novos-suicidios-por-excesso-de-trabalho-no-pais/50000243-3763292>.

Acesso em: 12/10/2018.

EHRLICH, Eugen. Fundamentos da sociologia do direito. Trad. René Ernani Gertz. Brasília: Editora Universidade de Brasília, 1986.

ESTRADA, Manuel Martin Pino. O teletrabalho na prestação de serviço. Revista da Ajuris, Porto Alegre, v.31, n.95, p. 185-200 set. 2004.

. Análise juslaboral do teletrabalho. Curitiba: Camões, 2008.

Teletrabalho: conceitos e a sua classificação em face aos avanços tecnológicos. In: COLNAGO, Lorena de Mello Rezende; CHAVES JUNIOR, José Eduardo de Resende; ESTRADA, Manuel Martín Pino (coords.). Teletrabalho. São Paulo: LTr, 2017, p. 11-19.

EUROFOUND AND THE INTERNATIONAL LABOUR OFFICE. Working anytime, anywhere: The effects on the world of work, Publications Office of the European Union, Luxembourg, and the International Labour Office, Geneva, 2017.

European Trade Union Confederation (ETUC); et al. Implementation of the European Framework Agreement on Telework: Report by the European Social Partners. Adopted by the Social Dialogue Committee on 28 june 2006. Disponível em: $<$ http://resourcecentre.etuc.org/linked_files/documents/Framework $\% 20$ agreement $\% 20 \mathrm{on} \%$ 20telework\%20EN.pdf>. Acesso em: $29 / 09 / 2018$. 
FAGAN, Colette; et al. The influence of working time arrangements on work-life integration or "balance": a review of the international evidence. Conditions of work and employment series. International Labour Office, Conditions of Work and Employment Branch. - Geneva: ILO, 2012, 67 p.

FELICIANO, Guilherme Guimarães; MIZIARA, Raphael (orgs.). Enunciados da $\mathbf{2}^{\mathbf{a}}$ Jornada de Direito Material e Processual do Trabalho: organizados por assunto. 2018. Disponível em: <https://www.anamatra.org.br/imprensa/noticias/26227-enunciadosaprovados-na-2-jornada-de-direito-material-e-processual-do-trabalho-sao-organizados-portema>. Acesso em: 16/10/2018.

- Nanotecnologia e meio ambiente do trabalho: sobre a tutela jusfundamental do trabalhador em horizontes de incerteza. In: ROCHA, Cláudio Jannotti da Rocha; et al (coords.). Proteção à saúde e segurança no trabalho. São Paulo: LTr, 2018, p. 130-135.

FELSTINER, Alek. Grappling with online work: lessons from cyberlaw. Saint Louis University Law Journal, Saint Louis, v.56, n.1., p.209-230, 2011.

FERNANDES, António de Lemos Monteiro. Direito do Trabalho. $13^{\mathrm{a}}$ ed. Coimbra: Edições Almedina, 2006.

FERNANDES, Francisco Liberal. Tempo de trabalho e tempo de descanso. In: APODIT Associação Portuguesa de Direito do Trabalho. Tempo de Trabalho e Tempos de não Trabalho: O Regime Nacional do Tempo de Trabalho à luz do Direito Europeu e Internacional. Lisboa: AAFDL, 2018, p. 11-23.

FERREIRA FILHO, Miguel. O meio ambiente laboral e a síndrome de burnout como acidente de trabalho: breves reflexões. In: GUNTHER, Luiz Eduardo; ALVARENGA, Rúbia Zanotelli de. (coords). Direitos humanos e meio ambiente do trabalho. São Paulo: LTr, 2016, p.115-125.

FIGUEIREDO, Guilherme José Purvin de. Direito ambiental e a saúde dos trabalhadores. São Paulo: LTr, 2000.

FINCATO, Denise Pires; CRACCO NETO, Heitor Barbieri. Teletrabalho: de Chappe a Nilles. Justiça do Trabalho, Porto Alegre, v. 30, n. 358, p. 52-66, out. 2013.

; NASCIMENTO, Carlota Bertoli. Teletrabalho e direitos fundamentais sociais: entre a modernidade sólida e a pós-modernidade líquida. Direitos Fundamentais e Justiça, Porto Alegre, v. 7, n. 24, p.196-215, jul./set. 2013.

; PIANTÁ, Eduardo. O pão nosso de cada dia em tempos de trabalho remoto: o fornecimento de alimentação ao empregado pelo empregador. Justiça do Trabalho, Porto Alegre, a. 32, n. 383, p. 58-75, nov. 2015.

FRANCO FILHO, Georgenor de Sousa. O teletrabalho e suas peculiaridades nas relações laborais. Repertório IOB de Jurisprudência. São Paulo, caderno 2, n. 6, p. 118-115, 2. quinz. mar. 1997. 
. Novas formas de contratação urbanas e rurais. Revista Magister de Direito do Trabalho, Porto Alegre, v. 8, n. 45, p. 13-23, nov./dez. 2011.

Intimidade e privacidade do trabalhador: direito internacional e comparado. São Paulo: LTr, 2016.

Reforma trabalhista em pontos: de acordo com a Lei $\mathbf{n} . \mathbf{1 3 . 4 6 7 / 1 7}$ e a MP n. 808/17. São Paulo: LTr, 2018.

GALINDO, Cristina. Quando as empresas são mais poderosas que os países. EL PAÍS Economia, 08 nov. 2017. Disponível em: $<$ https://brasil.elpais.com/brasil/2017/11/03/economia/1509714366_037336.html>. Acesso em: 23/09/2018.

GARAGNANI, Amanda Cristina. Teletrabalho: aspectos controvertidos. Revista do TRT 9a Região. Curitiba, a. 39, n. 71, p. 29-55, jan./dez. 2014.

GAUTHIER, Gustavo. Perspectiva laboral del teletrabajo. Revista Síntese Trabalhista e Previdenciária. Porto Alegre, a. 23, n. 272, p. 111-123, fev. 2012.

GHOSHEH, Naj. Remembering rest periods in law: Another tool to limit excessive working hours. Conditions of work and employment series, $n^{\circ} 78$. International Labour Office, Inclusive Labour Markets, Labour Relations and Working Conditions Branch. - Geneva: ILO, 2016, $32 \mathrm{p}$.

GIMÉNEZ, José Ignacio; MOLINA CHUECA, Jose Alberto; VELILLA, Jorge. Telework, the Timing of Work, and Instantaneous Well-Being: Evidence from Time Use Data. IZA Discussion Paper No. 11271. SSRN. Postado em: 29 jan. 2018. Disponível em: $<$ https://ssrn.com/abstract=3111144>. Acesso em: 20/10/2018.

GOMES, Orlando; GOTTSCHALK, Elson. Curso de direito do trabalho. $9^{\text {a }}$ ed. Rio de Janeiro: Forense, 1984.

GOMES, Júlio Manuel Vieira. Direito do Trabalho: relações individuais de trabalho. Vol. 1. Coimbra: Coimbra Editora, 2007.

GOTTSCHALK, Elson. A duração do trabalho: jornada, semana, descansos, trabalho noturno, quadro de horário, penalidades. Rio de Janeiro: Livraria Freitas Bastos, 1951.

HUSEK, Carlos Roberto. Curso básico de direito internacional público e privado do trabalho. $3^{\text {a }}$ ed. São Paulo: LTr, 2015.

INTERNATIONAL LABOUR OFFICE. Making work more human: working conditions and environment. Report of the Director-General: first item on the agenda. Geneva, 1975a. Disponível em: <http://www.ilo.org/public/libdoc/ilo/P/09605/09605(197560).pdf $>$. Acesso em: 09/10/2018.

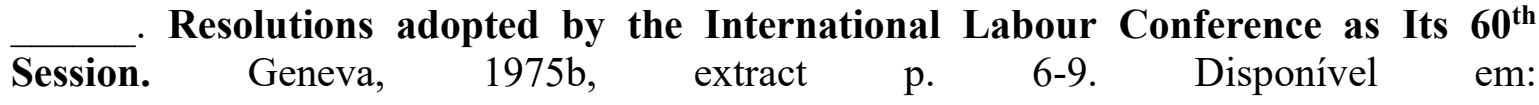


$<$ http://www.ilo.org/public/libdoc/ILO_Chronology/09734(1975-60)6-9.pdf $>$. Acesso em: $09 / 10 / 2018$.

International Programme for the Improvement of Working Conditions and

Environment. Geneva, May-June 1976. Disponível em: $<$ https://www.ilo.org/public/libdoc/ilo/GB/200/GB.200_PFA_10_8_engl.pdf > Acesso em: $09 / 10 / 2018$.

IWASAKI, Kenji; TAKAHASHI, Masaya; NAKATA, Akinori. Health problems due to long working hours in Japan: working hours, workers' compensation (Karoshi), and preventive measures. Industrial health, v. 44, n. 4, p. 537-540, 2006. Disponível em: $<$ https://www.jstage.jst.go.jp/article/indhealth/44/4/44_4_537/_pdf $>$. Acesso em: 09/07/2017.

JEAMMAUD, Antoine. Direito do Trabalho em transformação: tentativa de avaliação. In: JEAMMAUD, Antoine; ALVIM, Joaquim Leonel de Rezende; FRAGALE FILHO, Roberto. Trabalho, cidadania \& magistratura. Rio de Janeiro: Edições Trabalhistas, 2000a, p. 1-30.

. A questão do futuro do Direito do Trabalho. Visão da Europa. In: JEAMMAUD, Antoine; ALVIM, Joaquim Leonel de Rezende; FRAGALE FILHO, Roberto. Trabalho, cidadania \& magistratura. Rio de Janeiro: Edições Trabalhistas, 2000b, p. 31-60.

As transformações do trabalho e seus reflexos nos tribunais. In: JEAMMAUD, Antoine; ALVIM, Joaquim Leonel de Rezende; FRAGALE FILHO, Roberto. Trabalho, cidadania \& magistratura. Rio de Janeiro: Edições Trabalhistas, 2000c, p. 61-74.

. A Experiência Francesa de Redução da Jornada de Trabalho. In: MANNRICH, Nelson; et al (coords.). Reconstrução do direito do trabalho: anais da Academia Nacional do Direito do Trabalho. São Paulo: LTr, 2010, p. 26-45.

KAPLAN, Seth; ENGELSTED, Lia; LEI, Xue; LOCKWOO, Karla. Unpackaging Manager Mistrust in Allowing Telework: Comparing and Integrating Theoretical Perspectives. J Bus Psychol, 2018, 33, p. 365-382. Disponível em: <https://link-springercom.ez67.periodicos.capes.gov.br/content/pdf/10.1007\%2Fs10869-017-9498-5.pdf $>$.

Acesso em: 19/10/2018.

KELSEN, Hans. Teoria pura do direito. Trad. João Baptista Machado. $7^{\mathrm{a}}$ ed. São Paulo: Martins Fontes, 2006.

KIVIMÄKI, Mika et al. Long working hours and risk of coronary heart disease and stroke: a systematic review and meta-analysis of published and unpublished data for 603.838 individuals. The Lancet, Aug. 2015. Disponível em: $<$ http://www.thelancet.com/journals/lancet/article/PIIS0140-6736(15)60295-1/fulltext>. Acesso em: 09/07/2017.

LEINEWEBER, Constanze; et al. Parent's Relative Perceived Work Flexibility Compared to Their Partner Is Associated With Emotional Exhaustion. Frontiers in Psychology [16641078], 2018, vol.: 9 p. 640-640. Disponível em: 
$<$ https://www.ncbi.nlm.nih.gov/pmc/articles/PMC5943972/pdf/fpsyg-09-00640.pdf>. Acesso em: 20/10/2018.

LIMA FILHO, Francisco das C. O reconhecimento legal da relação de emprego do teletrabalhador. Revista LTr. São Paulo, ano 76, nº 1, jan-2012, p. 34-38.

LOS ANGELES COUNTY. Department of Human Resources. Telework Program: policy and procedures: A guide to telework for Los Angeles County Employees and Supervisors. August 2017. Disponível em: <http://rideshare.lacounty.gov/wpcontent/uploads/2018/03/Telework-Manual-08-17-2017.pdf $>$. Acesso em: 04/07/2018.

MALLET, Estêvão. Trabalho, tecnologia e subordinação: reflexões sobre a Lei n. 12.551. Revista do Advogado. São Paulo, a. 32, n. 115, p. 44-52, abr. 2012.

MANNRICH, Nelson. Inspeção do trabalho. São Paulo: LTr, 1991a.

. Saúde, higiene e segurança. In: ROMITA, Arion Sayão. Estudos em homenagem ao Professor Amauri Mascaro Nascimento. LTr: 1991b, p. 254-273.

. Limites da flexibilização das normas trabalhistas. Revista do Advogado Associação dos Advogados de São Paulo, nº 54, dez. 1998, p. 29-36.

. Natureza, limites e finalidade da inspeção do trabalho: a Justiça do Trabalho e as ações relativas às penalidades administrativas. Revista de Direito do Trabalho, ano 32, janmar. 2006, p. 208-232.

Operadores de teleatendimento (telemarketing): algumas reflexões. Revista do Tribunal Regional do Trabalho da $1^{\text {a }}$ Região, $n^{0} 48$, jul-dez 2010, p. 69-79.

. Reconstrução do Direito do Trabalho. In: MARTINS FILHO, Ives Gandra; MANNRICH, Nelson; PRADO, Ney (coords.). Os Pilares do direito do trabalho. São Paulo: Lex Editora, 2013, p. 559-583.

. Futuro do Direito do Trabalho, no Brasil e no mundo. Revista LTr. São Paulo, vol.

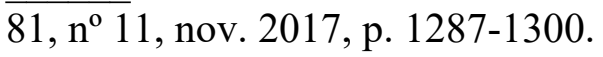

MARINHO, Kamila. Teletrabalho é tema de Audiência Pública na Câmara Municipal. Câmara Municipal de São Paulo, 16 abr. 2018. Disponível em: $<$ http://www.saopaulo.sp.leg.br/blog/teletrabalho-e-tema-de-audiencia-publica-na-camaramunicipal/>. Acesso em: 16/10/2018.

MARTINS, Helena. Trabalho intermitente, parcial e teletrabalho já devem ser informados ao CAGED. Agência Brasil. Economia, 01 dez. 2017. Disponível em: < http://agenciabrasil.ebc.com.br/economia/noticia/2017-12/trabalho-intermitente-parcial-eteletrabalho-ja-devem-ser-informados-ao>. Acesso em: 03/01/2019.

MARTINS, João Zenha. Tempo de trabalho e tempo de repouso: qualificação e delimitação de conceitos. In: APODIT - Associação Portuguesa de Direito do Trabalho. Tempo de Trabalho e Tempos de não Trabalho: $O$ Regime Nacional do Tempo de Trabalho à luz do Direito Europeu e Internacional. Lisboa: AAFDL, 2018, p. 25-67. 
MARTINS, Sérgio Pinto. Teletrabalho. Repertório IOB de Jurisprudência: Trabalhista e Previdenciário. São Paulo, v. 2, nº 18, p. 352-349, 2011.

MAZZUCCHELLI, Frederico. A crise em perspectiva: 1929 e 2008. Novos estud. CEBRAP, São Paulo, n. 82, p. 57-66, nov. 2008. Disponível em: $<$ http://www.scielo.br/scielo.php?script $=$ sci_arttext\&pid $=$ S0101$33002008000300003 \& \operatorname{lng}=$ en\&nrm=iso>. Acesso em: 02/01/2019.

MEDINA, Paloma Fraga. KRAWULSKI, Edite. Coworking como modalidade e espaço de trabalho: uma análise bibliomética. Cadernos de Psicologia Social do Trabalho, 2015, vol. 18, n. 2, p.181-190 - DOI: 10.11606/issn.1981-0490.v18n2p181-190 Disponível em: $<$ https://www.revistas.usp.br/cpst/article/view/125804/122803>. Acesso em: 07/07/2018.

MELEK, Marlos Augusto. Trabalhista! O que mudou? - Reforma Trabalhista 2017. Curitiba: Estudo Imediato Editora, 2017.

MELO, Raimundo Simão de. Direito ambiental do trabalho e saúde do trabalhador: responsabilidades legais, dano material, dano moral, dano estético, indenização pela perda de uma chance, prescrição. $5^{\text {a }}$ ed. São Paulo: LTr, 2013.

- A reforma trabalhista e o direito tutelar do trabalho referente às normas de saúde e segurança do trabalho. In: A reforma trabalhista na visão da Academia Brasileira de Direito do Trabalho. Porto Alegre: LexMagister, 2018, p. 345-367.

MELO, Sandro Nahmias; RODRIGUES, Karen Rosendo de Almeida Leite. Direito à desconexão do trabalho: com análise crítica da reforma trabalhista: (Lei $n$. 13.467/2017). São Paulo: LTr, 2018.

. Teletrabalho, controle de jornada e direito à desconexão. In: MARTINEZ, Luciano; et al. (coords.). In: A reforma trabalhista na visão da Academia Brasileira de Direito do Trabalho. Porto Alegre: LexMagister, 2018, p. 154-164.

MINISTÉRIO DO TRABALHO. Dados estatísticos de saúde e segurança do trabalho. 2016. Consolidados por setor econômico (continuação série histórica). Disponível em: $<$ http://trabalho.gov.br/dados-abertos/estatistica-saude-e-seguranca-do-trabalho/segurancatrabalho-2016>. Acesso em: 04/11/2018.

MURGAS, Rolando. Contrato de trabalho transnacional. In: ZAINAGHI, Domingos Sávio; FREDIANI, Yone. Novos rumos de direito do trabalho na América Latina. São Paulo: LTr, 2003, p. 48-62.

MYODO, Emi; et al. Issues and Solutions to Informal Communication in Working from Home Using a Telepresence Robot. ITE Trans. on MTA Vol. 6, No. 1, pp. 30-45 (2018). Disponível em: <https://www.jstage.jst.go.jp/article/mta/6/1/6_30/_pdf/-char/en>. Acesso em: 19/10/2018.

MORAES FILHO, Evaristo de. Trabalho a domicílio e contrato de trabalho. São Paulo: LTr, 1994. 
MOREIRA, Teresa Alexandra Coelho. Algumas notas sobre as novas tecnologias de informação e comunicação e o contrato de teletrabalho subordinado. Scientia Iuridica, Braga, v.63, n.335, maio/ago. 2014.

A privacidade dos trabalhadores e a utilização das redes sociais online: algumas questões. In: MOREIRA, Teresa Alexandra Coelho. Estudos de direito do trabalho. Vol. II. Coimbra: Edições Almedina, 2016a, p. 11-69.

O controlo dos trabalhadores através de sistemas de geolocalização. In: MOREIRA, Teresa Alexandra Coelho. Estudos de direito do trabalho. Vol. II. Coimbra: Edições Almedina, 2016b, p. 89-117.

NASCIMENTO, Amauri Mascaro. Motivos de las horas extraordinarias en los trabajos industriales en el Brasil. In: VVAA. La Jornada Extraordinaria en América Latina. Organización Internacional del Trabajo. LIMA: Centro Interamericano de Administración del Trabajo (CIAT), 1986, p. 201-290.

. Teoria jurídica do salário. São Paulo: LTr, 1994.

Curso de direito do trabalho: história e teoria geral do direito do trabalho: relações individuais e coletivas do trabalho. 25. ed. São Paulo: Saraiva, 2010a.

. O Problema da Redução da Jornada de Trabalho e o Direito Brasileiro. In: MANNRICH, Nelson; et al (coords.). Reconstrução do direito do trabalho: anais da Academia Nacional do Direito do Trabalho. São Paulo: LTr, 2010b, p. 17-25.

. O trabalho a distância e os meios informatizados de controle e supervisão. In: Revista do Advogado, São Paulo, v. 33, n. 121, p. 15-17, nov. 2013.

NILLES, Jack M. Fazendo do teletrabalho uma realidade: um guia para telegerentes e teletrabalhadores. Tradução de Eduardo Pereira e Ferreira. São Paulo: Futura, 1997.

NUNES, João Paulo Avelãs. Da “Crise de 1929" à “Crise de 2008”. Reflexão historiográfica em torno do conceito de "Estado Providência". I\&D CEIS20 - Artigos em Revistas Nacionais. 2013. Disponível em: <https:/estudogeral.uc.pt/handle/10316/46457>. Acesso em: 02/01/2019.

NUNES, Luiz Antônio Rizzatto. Manual de introdução ao estudo do direito: com exercícios para sala de aula e lições de casa. $6^{\mathrm{a}}$ ed. rev. atual. e ampl. São Paulo: Saraiva, 2005.

NUNES, Talita Camila Gonçalves. O Acidente de Teletrabalho e a Fiscalização da Tecnologia da Telemática: aspectos e consequências do teleassédio moral e do teletrabalho escravo. In: COLNAGO, Lorena de Mello Rezende; CHAVES JUNIOR, José Eduardo de Resende; ESTRADA, Manuel Martín Pino (coords.). Teletrabalho. São Paulo: LTr, 2017, p. 107-118.

. A advocacia conhecendo o teletrabalho: origem, conceitos e regulamentação na Lei 13.467/2017 - Reforma Trabalhista. In: BOUCINHAS FILHO, Jorge Cavalcanti; et al (coords.). Reforma trabalhista na visão da advocacia: Aspectos práticos e estratégias para o cotidiano. São Paulo: Thomson Reuters Brasil, 2018, p. 165-185. 
OLIVEIRA, Sebastião Geraldo de. Proteção jurídica à saúde do trabalhador. $6^{\mathrm{a}}$ ed. rev. e atual. São Paulo: LTr, 2011.

OLIVEIRA NETO, Célio Pereira. Trabalho em ambiente virtual: causas, efeitos e conformação. São Paulo: LTr, 2018.

ORGANIZACIÓN INTERNACIONAL DEL TRABAJO. Tesauro de la OIT. Disponível em: <http://ilo.multites.net/defaultes.asp >. Acesso em: 08/04/2018.

PALMA RAMALHO, Maria do Rosário. Tratado de direito do trabalho. Parte I Dogmática geral. Coimbra: Edições Almedina, 2012.

. Tempo de trabalho e conciliação entre a vida profissional e a vida familiar - algumas notas. In: APODIT - Associação Portuguesa de Direito do Trabalho. Tempo de Trabalho e Tempos de não Trabalho: $O$ Regime Nacional do Tempo de Trabalho à luz do Direito Europeu e Internacional. Lisboa: AAFDL, 2018, p. 101-116.

PAMPLONA, Rodolfo; FERNANDEZ, Leandro. Tecnologia da informação e as relações de trabalho no Brasil: o teletrabalho na Lei $n^{0} 13.467 / 17$. Revista Direito UNIFACS, $n$. 2016, jun. 2018, 25 p.

PASTORE, José. Evolução tecnológica: repercussões nas relações do trabalho. Revista de Direito do Trabalho, São Paulo, v.31, n.119, p.163-184, jul./set. 2005.

PEREIRA, Ricardo José Macêdo de Britto Pereira. Saúde, higiene e segurança no trabalho no contexto do trabalho digno. A fragmentação do meio ambiente de trabalho operada pela reforma trabalhista. In: ROCHA, Cláudio Jannotti da Rocha; et al (coords.). Proteção à saúde e segurança no trabalho. São Paulo: LTr, 2018, p. 259-268.

PERES, Antonio Galvão. Contrato internacional de trabalho: novas perspectivas. São Paulo: LTr, 2004.

PINTO, José Augusto Rodrigues. Ambientes saudáveis de trabalho. In: FELICIANO, Guilherme Guimarães; et al (coords.). Direito ambiental do trabalho: apontamentos para uma teoria geral, v. 2, São Paulo: LTr, 2015, p. 81-87.

PRADO, Luis Carlos Delorme. A Grande Depressão e a Grande Recessão: Uma comparação das crises de 1929 e 2008 nos EUA. Revista Econômica, Niterói, v. 13, n. 2, dez. 2011, p. $9-44$.

PRAGMÁCIO FILHO, Eduardo. Teoria da empresa para o direito do trabalho brasileiro. São Paulo: LTr, 2018.

PRATA, Marcelo Rodrigues. As normas de duração do trabalho não mais pertencem à ambiência laboral? In: A reforma trabalhista na visão da Academia Brasileira de Direito do Trabalho. Porto Alegre: LexMagister, 2018, p. 368-381.

RASO DELGUE, Juan. La empresa virtual: nuevos retos para el Derecho del Trabajo. Revista Internacional y Comparada de RELACIONES LABORALES Y DERECHO 
DEL EMPLEO. Vol. 5, núm. 1, enero-marzo de 2017, p. 2-39. Disponível em: $<$ http://ejcls.adapt.it/index.php/rlde_adapt/article/view/454/621>. Acesso em: 07/07/2018.

RAYMOND, Wilfredo Sanguineti. El teletrabajo: notas sobre su noción, calificación y régimen jurídico. In: RAYMOND, Wilfredo Sanguineti. Derecho del Trabajo: Tendencias contemporáneas. Lima: Editora y Librería Jurídica Grijley: 2013a, p. 100-120.

. El desafío de la transnacionalización del empleo: teletrabajo, nuevas tecnologías y dumping social. In: RAYMOND, Wilfredo Sanguineti. Derecho del Trabajo: Tendencias contemporáneas. Lima: Editora y Librería Jurídica Grijley: 2013b, p. 142-172.

REALE, Miguel. Lições preliminares de direito. $27^{\mathrm{a}}$ ed. ajustada ao novo código civil. São Paulo: Saraiva, 2002.

RIBEIRO, Thiago Reis Marques. New Deal e origens do Eximbank. Revista Mosaico, v. 9, $\mathrm{n}^{\mathrm{o}} 1$, p. 35-55, jan.-jun. 2016.

RIFKIN, Jeremy. El fin del trabajo. Nuevas tecnologías contra puestos de trabajo: el nacimiento de una nueva era. Trad. Guillermo Sánchez. Barcelona: Colección Booket, 2004.

ROCHA, Antonio Penalves. As observações de Jean-Baptiste Say sobre a escravidão. Estud. av., São Paulo, v. 14, n. 38, p. 181-212, abr. 2000. Disponível em: $<$ http://www.scielo.br/scielo.php?script=sci_arttext\&pid=S0103-

$40142000000100009 \& \operatorname{lng}=$ en\&nrm=iso $>$. A cesso em: 02/01/2019.

RUTH, Stephen. The Dark Side of Telecommuting - Is a Tipping Point Approaching? (July 7, 2011). GMU School of Public Policy Research Paper No. 2012-02. Disponível no SSRN: <https://ssrn.com/abstract=1880895>. Acesso em: 21/10/2018.

SARBU, Miruna. The role of telecommuting for work-family conflict among German employees. Research in Transportation Economics (2018). Disponível em: $<$ https://doi.org/10.1016/j.retrec.2018.07.009>. Acesso em: 19/10/2018.

SCHAFF, Adam. A sociedade informática: as consequências sociais da segunda revolução industrial. Trad. Carlos Eduardo Jordão Machado e Luiz Arturo Obojes. $4^{\mathrm{a}}$ ed. São Paulo: Editora da Universidade Paulista: Brasiliense, 1995.

SCHWAB, Klaus. A quarta revolução industrial. Trad. Daniel Moreira Miranda. São Paulo: Edipro, 2016.

SEGARRA, María Serrano. La crisis económica de 1929: Roosevelt y el New Deal. Revista de la Facultad de Ciencias Sociales y Jurídicas del Elche, vol. I, no 6, mar. 2010, p. 112 130 .

SICHES, Luis Recasens. Tratado general de filosofía del derecho. $20^{\mathrm{a}}$ ed. México: Editorial Porrúa, 2010.

SIERRA BENÍTEZ, Esperanza Macarena. El contenido de la relación laboral en el teletrabajo. $1^{\text {a }}$ ed. Sevilla: Consejo Económico y Social de Andalucía, 2011. 
SILVA, Alessandro da. Ato inseguro, culpabilização das vítimas e o papel do nexo de causalidade na responsabilidade por acidentes do trabalho. In: FELICIANO, Guilherme Guimarães; et al (coords.). Direito ambiental do trabalho: apontamentos para uma teoria geral, v. 2, São Paulo: LTr, 2015, p. 465-480.

SILVA, Bruno Mattos. A desregulamentação dos mercados financeiros e a crise global: lições e perspectivas. Senatus, Brasília, v. 8, nº 2, out. 2010, p. 14-28.

SILVA, Homero Batista Mateus da. Curso de direito do trabalho aplicado: saúde e segurança do trabalho. $3^{\mathrm{a}}$ ed. rev., atual. e ampl. São Paulo: Editora Revista dos Tribunais, 2017a.

$2017 b$.

Comentários à reforma trabalhista. São Paulo: Editora Revista dos Tribunais,

SILVA, José Antônio Ribeiro de Oliveira. A flexibilização da jornada de trabalho e seus reflexos na saúde do trabalhador: uma questão de tutela ambiental. In: FELICIANO, Guilherme Guimarães; et al (coords.). Direito ambiental do trabalho: apontamentos para uma teoria geral, v. 2, São Paulo: LTr, 2015, p. 183-202.

SILVA, Luiz de Pinho Pedreira da. O teletrabalho. Revista LTr. São Paulo, a. 64, t. I, n. 5, p. 583-587, maio 2000 .

SILVA, Virgílio Afonso da. O proporcional e o razoável. Revista dos Tribunais, 798, 2002, p. 23-50.

SOBRATT (Sociedade Brasileira de Teletrabalho e Teleatividades). Disponível em: $<$ http://www.sobratt.org.br>. Acesso em: 23/12/2017.

SOBRINHO, Juliano Custódio. Sobre um tempo de incertezas: o processo de abolição e os significados da liberdade em Minas Gerais (1880-1888). 294 p. Tese de Doutorado. Faculdade de Filosofia, Letras e Ciências Humanas, da Universidade de São Paulo. São Paulo. 2014.

SOUSA; Duarte Abrunhosa e. Registo dos tempos de trabalho e proteção de dados pessoais. In: APODIT - Associação Portuguesa de Direito do Trabalho. Tempo de Trabalho e Tempos de não Trabalho: $O$ Regime Nacional do Tempo de Trabalho à luz do Direito Europeu e Internacional. Lisboa: AAFDL, 2018, p. 117-.

SOUSA JÚNIOR, Antonio Umberto de; et al. Reforma trabalhista: análise comparativa e crítica da Lei no 13.467/2017 e da Med. Prov. nº 808/2017. São Paulo: Rideel, 2018.

SOUTH COAST AIR QUALITY MANAGEMENT DISTRICT. RULE 2202 - ONROAD MOTOR VEHICLE MITIGATION OPTIONS EMPLOYEE COMMUTE REDUCTION PROGRAM GUIDELINES. February, 2016. Disponível em: $<$ http:/www.aqmd.gov/docs/default-source/rule-book/support-documents/rule-2202/rule2202-employee-commute-reduction-program-guidelines-(ecrp).pdf?sfvrsn=10>. Acesso em: 04/07/2018. 
SOUTO MAIOR, Jorge Luiz. Do direito à desconexão do trabalho. Revista do Tribunal Regional do Trabalho da 15 $^{\text {a }}$ Região, Campinas, SP, n. 23, p. 296-313, jul./dez. 2003.

STOLZ, Sheila; FORTALEZA, Jesús Lahera. Igualdade de tratamento e não discriminação por razão de gênero e a nova legislação espanhola sobre teletrabalho. In: COLNAGO, Lorena de Mello Rezende; CHAVES JUNIOR, José Eduardo de Resende; ESTRADA, Manuel Martín Pino (coords.). Teletrabalho. São Paulo: LTr, 2017, p. 135-154.

STÜRMER, Gilberto; PEREIRA, Juliana Hörlle. Teletrabalho: controle de jornada de meio ambiente laboral. Justiça do Trabalho, Porto Alegre, v.30, n. 354, p.7-37, jun. 2013.

SUPIONI JUNIOR, Claudimir. Teoria da eficácia ultraterritorial das normas coletivas de trabalho. 2017. $226 \mathrm{f}$. Tese (Doutorado em Direito) - Programa de Estudos PósGraduados em Direito, Pontifícia Universidade Católica de São Paulo, São Paulo, 2017.

SUPIOT, Alain. Critique du droit du travail. Paris: Presses Universitaires de France, 1994.

; et al. Transformações do trabalho e futuro do Direito do Trabalho na Europa.

Trad.: Serviços de Tradução da Comissão Europeia. Coimbra: Coimbra Editora, 2003.

SÜSSEKIND, Arnaldo. Direito constitucional do trabalho. Rio de Janeiro: Renovar, 1999. $\overline{\mathrm{LTr}, 2000 .}$

Direito internacional do trabalho. $3^{a}$ ed. atual. e com novos textos. São Paulo:

TEUBNER, Gunther. A Bukowina Global sobre emergência de um pluralismo jurídico transnacional. Impulso: Revista de Ciências Sociais e Humanas, v. 14, n. 33, 2003, p. 931.

TREVISAN, Alexandre; et al. Pesquisa Home Office Brasil 2016. SAP Consultoria em Recursos Humanos. Disponível em: <http://www.sobratt.org.br/index.php/11-e-12052016estudo-home-office-brasil-apresenta-o-cenario-atual-da-pratica-no-pais-sap-consultoria/>. Acesso em: 03/11/2018.

TUCKER, Philip; FOLKARD, Simon. Working Time, Health, and Safety: a Research Synthesis Paper. Conditions of Work and Employment Series, No. 31. INTERNATIONAL LABOUR OFFICE - GENEVA, 2012, 67 p.

ȚOP, Dan Cristian. Regulatory of the Teleworking Activities in Romania (April 6, 2018). SSRN. Disponível em: <https://ssrn.com/abstract=3157517>. Acesso em: 20/10/2018.

TUPINAMBÁ, Carolina. A jornada de trabalho e a Lei n. 13.467/2017: o esvaziar da ampulheta na nova lógica da contagem do tempo de trabalho. Revista do Tribunal Regional do Trabalho da $3^{\text {a }}$ Região, Belo Horizonte, edição especial, nov. 2017, p. 49-66.

TVANAMATRA. Presidente da Anamatra aponta inconstitucionalidades da reforma trabalhista. Publicado em 28 jun. 2017. Disponível em: $<$ https://www.youtube.com/watch?v=b8PyLHo6U9U>. Acesso em: 08/10/2018. 
VALENCIA CATUNTA, Ana Maria Cecilia. Aspectos regulatorios del teletrabajo en el Perú: análisis y perspectivas. Rev. IUS, Puebla, v. 12, n. 41, p. 203-226, jun. 2018. Disponível em: $\quad<\mathrm{http}: / / \mathrm{www}$.scielo.org.mx/scielo.php?script=sci_arttext\&pid=S187021472018000100203\&lang=pt>. Acesso em: 20/10/2018.

VALENTIM, João Hilário. Teletrabalho e relações de trabalho. Revista do Ministério Público do Trabalho. Brasília, a. 10, n. 19, p. 96-104, mar. 2000.

VILLATORE, Marco Antônio César; RODRIGUES JUNIOR, Edison Luiz. Novidades sobre o teletrabalho e a Lei n. 13.467, publicada em 13 de julho de 2017. O avanço legislativo e o retrocesso de direitos. In: DALLEGRAVE NETO, José Affonso; KAJOTA, Ernani (coords.). Reforma trabalhista ponto a ponto: estudos em homenagem ao professor Luiz Eduardo Gunther. São Paulo: LTr, 2018, p. 78-84.

WINTER, Vera Regina Loureiro. Teletrabalho: uma forma alternativa de emprego. São Paulo: LTr, 2005.

ZYLBERSTAJN, Hélio. Aspectos Econômicos da Redução da Jornada de Trabalho. In: In: MANNRICH, Nelson; et al (coords.). Reconstrução do direito do trabalho: anais da Academia Nacional do Direito do Trabalho. São Paulo: LTr, 2010, p. 63-71. 